\title{
Dual role of interleukin-10 in the regulation of respiratory syncitial virus (RSV)-induced lung inflammation
}

L. Sun ${ }^{\star}$ T. T. Cornell, ${ }^{\star}$ A. LeVine, ${ }^{\star}$ A. A. Berlin, ${ }^{\dagger}$ V. Hinkovska-Galcheva, ${ }^{\star}$ A. J. Fleszar, ${ }^{\star}$ N. W. Lukacs ${ }^{\dagger}$ and T. P. Shanley ${ }^{\star}$

${ }^{*}$ Division of Critical Care Medicine, C.S Mott Children's Hospital and the Department of Pediatrics and Communicable Diseases, and ${ }^{\dagger}$ Department of Pathology, University of Michigan Medical School, Ann Arbor, MI, USA

Accepted for publication 17 December 2012 Correspondence: T. P. Shanley, Division of Critical Care Medicine, Department of Pediatrics and Communicable Diseases, University of Michigan Medical School, 109 Zina Pitcher Place, 4460 BSRB, Ann Arbor, MI 48109, USA.

E-mail: tshanley@med.umich.edu

\section{Summary}

RSV lower respiratory tract infections (LRTI) are among the most common diseases necessitating hospital admission in children. In addition to causing acute respiratory failure, RSV infections are associated with sequelae such as secondary bacterial infections and reactive airway disease. One characteristic host response observed in severe RSV-induced LRTI and/or subsequent development of asthma is increased expression of interleukin (IL)-10. However, contradictory results have been reported regarding whether IL-10 inhibits asthmatic responses or intensifies the disease. We aimed to reconcile these discordant observations by elucidating the role of IL-10 in regulating the host response to RSV LRTI. In this study, we used a lung-specific, inducible IL-10 over-expression (OE) transgenic mouse model to address this question. Our results showed that the presence of IL-10 at the time of RSV infection not only attenuated acute inflammatory process (i.e. $24 \mathrm{~h}$ postinfection), but also late inflammatory changes [characterized by $\mathrm{T}$ helper type 2 (Th2) cytokine and chemokine expression]. While this result appears contradictory to some clinical observations where elevated IL-10 levels are observed in asthmatic patients, we also found that delaying IL-10 OE until the late immune response to RSV infection, additive effects rather than inhibitory effects were observed. Importantly, in non-infected, IL-10 OE mice, IL-10 OE alone induced up-regulation of Th2 cytokine (IL-13 and IL-5) and Th2-related chemokine [monocyte chemoattractant protein 1 (MCP-1), chemokine (C-C motif) ligand 3 (CCL3) and regulated upon activation normal $\mathrm{T}$ cell expressed and secreted (RANTES)] expression. We iden-

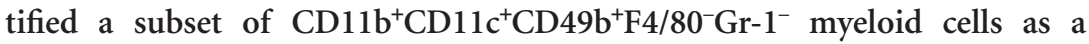
prinicipal source of IL-10-induced IL-13 production. Therefore, the augmented pathological responses observed in our 'delayed' IL-10 overexpression model could be attributed to IL-10 OE alone. Taken together, our study indicated dual roles of IL-10 on RSV-induced lung inflammation which appear to depend upon the timing of when elevated IL-10 is expressed in the lung.

Keywords: chemokines, pulmonary inflammation, RSV, Th1, Th2 cytokines

\section{Introduction}

Viral infections of the respiratory tract result in a broad spectrum of disease presentations, ranging from the common cold to respiratory failure and occasionally death. Clinical consequences of viral-triggered lower respiratory tract infections (LRTI) such as bronchiolitis, apnoea and asthma exacerbations are among the most prevalent causes of acute hospitalizations in children. The epidemiological role of respiratory syncytial virus (RSV) on mediating these presentations in children is well defined [1-4]. Further, several epidemiological studies have implicated childhood RSV LRTI as an independent risk factor for the subsequent development of chronic asthma [5,6], although we have an incomplete understanding of the mechanistic role of RSV in causing this late sequela. 
RSV is an enveloped, non-segmented, negative-sense, single-stranded RNA virus whose genome encodes at least 11 different viral proteins. Unexpectedly, vaccine development against recombinant surface proteins not only failed to confer protection, but actually led to more severe pulmonary disease upon RSV infection [7]. Similarly, an earlier approach of challenging a vaccinated cohort with RSV induced interleukin (IL)-10 and IL-4 production, accompanied by exacerbation of lung histopathology [8]. These results from the development of an RSV vaccine as well as the extraordinary burden of disease necessitate an improved understanding of the host response to RSV LRTI to identify alternative therapeutic strategies.

IL-10 is a major anti-inflammatory cytokine. As stated, it would be expected that in responses triggered by RSV, IL-10 expression is a necessary and beneficial host response directed at regulating excessive proinflammatory cytokines and chemokines from RSV-activated immune cells $[9,10]$. Clinically, however, controversial data have been reported for the role of IL-10 in modulating RSV-induced inflammation. For instance, increased IL-10 and regulated upon activation normal $\mathrm{T}$ cell expressed and secreted (RANTES) were found in nasopharyngeal secretions of children infected with RSV [11], and this observation is consistent with another 1-year follow-up study which showed that high IL-10 was associated with post-bronchiolitis wheezing $[12,13]$. Conversely, lower IL-10 levels were reported to be associated with a higher frequency of bronchial asthma and chronic obstructive pulmonary disease (COPD) [14,15]. Furthermore, helminth-infected asthmatic patients with lower levels of IL-10 tended to have less T helper type 2 (Th2) cytokine production when compared to helminthfree patients [16]. These discrepancies suggest that IL-10 may be a dual function cytokine that plays multiple roles in modulating varied immune responses during RSV infections. In this study we utilized a lung-specific IL-10 overexpression (OE) murine model to examine specifically the effects of IL-10 on RSV-induced lung inflammation. As IL-10 OE can be manipulated temporally by giving animals a doxy-containing diet, we were able to investigate IL-10 effects at different stages of RSV infection (i.e. early phase and late phase). Our results showed that indeed IL-10 plays dual roles during RSV infection. While the presence of IL-10 at the time of RSV infection inhibited both acute and late inflammation, late OE of IL-10 caused further exacerbation of RSV-induced lung pathophysiology.

\section{Materials and methods}

\section{Animals}

All animal experiments were performed in accordance with the National Institutes of Health guidelines and locally approved by the University of Michigan's Committee on Use and Care of Animals (UCUCA). The tetracycline- inducible, lung-specific human IL-10 OE transgenic FVB/n mice were established previously in the laboratory [17]. Chow containing tetracycline $(0 \cdot 0625 \%)$ was purchased as TestDiet from Purina (Richmond, IN, USA). With this methodology, we achieve lung-specific, human IL-10 OE at about half-maximal levels at day 3 and maximal expression levels by day 5 following ad libitum access to TestDiet. Thus, in this study mice were provided tetracycline chow ad libitum 3 days prior to RSV intratracheal injection. To determine the impact of IL-10 OE after the initiation of RSV infection, tetracycline chow was provided 2 days after RSV intratracheal injection in order to induce IL-10 OE later in the disease course. Previous investigations have characterized control mice [FVB/n wild-type, and single transgenic mouse possessing only the tet-responsive, human IL-10 construct (tet-O-CMV-huIL-10)], none of which demonstrated tetracycline-inducible human IL-10 expression [17]. Therefore, in this study, 6-8 weeks single transgenic $\mathrm{FVB} / \mathrm{n}$ control mice (designated as 'TG-') and bitransgenic mice (designated as 'IL-10 OE') were both provided ad libitum access to TestDiet.

\section{RSV infection}

Human RSV A strain isolated originally at the University of Michigan Hospitals was grown in culture and isolated. The ability of this isolate to induce acute lung injury has been characterized previously, as reported extensively [18-21]. For RSV infection with this strain, mice were anaesthetized with inhalational isoflurane and injected intratracheally with $\sim 1 \times 10^{5}$ plaque-forming units (pfu) of virus. The animals were examined at various time-points after challenge for chemokine and cytokine expression and histological analysis. Normal rabbit serum and anti-mouse IL-10 immune serum utilized for the anti-IL-10 blocking experiment were kindly provided by Dr Steven Kunkel at the University of Michigan. The protocol for intraperitoneal (i.p.) injection of the blocking serum has been described previously [22].

\section{Assessment of gene expression by real-time polymerase chain reaction $(\mathrm{PCR})$}

RNA was isolated from lung tissue following homogenization in Trizol (Invitrogen Life Technologies, Carlsbad, CA, USA), according to the manufacturer's protocol. Then, $1 \mu \mathrm{g}$ of total RNA was reverse-transcribed in a $20-\mu \mathrm{l}$ volume. Messenger RNA expression was determined in $2 \mu \mathrm{l}$ of cDNA by TaqMan real-time PCR using a Realplex detection system (Eppendorf, Inc., Hauppauge, NY, USA) with genespecific primers and probes labelled with $5^{\prime}$-FAM and 3'-TAMRA. Primers and probes used for the detection of mRNA expression were purchased from Applied Biosystems (Carlsbad, CA, USA). Primers and probes for RSV-n and RSV-g were determined using primer/probe detection sets 
designed by PE Biosystems and purchased from SigmaAldrich (St Louis, MO, USA) [23]. Reactions were incubated for $2 \mathrm{~min}$ at $50^{\circ} \mathrm{C}$, denatured for $10 \mathrm{~min}$ at $95^{\circ} \mathrm{C}$ and subjected to 40 two-step amplification cycles with annealing/extension at $60^{\circ} \mathrm{C}$ for $1 \mathrm{~min}$ followed by denaturation at $95^{\circ} \mathrm{C}$ for $15 \mathrm{~s}$. Murine glyceraldehyde-3phosphate-dehydrogenase (GAPDH) was used as an internal control for quantification of the total amount of cDNA used in the reaction. Results are normalized to GAPDH expression and presented as fold-increase in mRNA expression compared with the level detected in non-infected control mice.

\section{Bioplex assay}

Whole lung protein samples were prepared by homogenizing tissue in phosphate-buffered saline (PBS) containing $0 \cdot 1 \%$ Triton X-100 with protease inhibitor cocktail tablets (Roche, Indianapolis, IN, USA). Lung homogenates were spun at $15000 \mathrm{~g}$ for $10 \mathrm{~min}$. Supernatants were collected and stored at $-80^{\circ} \mathrm{C}$ until analysed for chemokine and cytokine expression by multiplex assay (Bio-Rad, Hercules, CA, USA).

\section{Assessment of lung pathology}

Mice lungs were dissected and inflation fixed in 10\% buffered formalin. The lungs were maintained in formalin for $24 \mathrm{~h}$ before being processed into paraffin blocks using standard histological techniques. Lung tissue sections were stained with both haematoxylin and eosin (H\&E) for analysis of peribronchial inflammatory cell accumulation and periodic acid-Schiff (PAS) for assessment of mucus production. To quantify mucus production in the lung, slides stained with PAS were examined at $\times 100$ final magnification using an Olympus IX71 microscope.

\section{Pulmonary leucocyte isolation and differential counting}

Animals were euthanized by an approved protocol and lungs were perfused with PBS via the right heart until pulmonary vessels were grossly clear. Lungs were bluntly dissected free from the chest cavity and minced to a slurry in a suspension of digest solution containing collagenase (15 mg), DNase I (250 KU units) and complete media (RPMI-10\% fetal calf serum). The suspension was incubated on a rocker for $30 \mathrm{~min}$ at $37^{\circ} \mathrm{C}$. The cells were dispersed by repetitive suction through a $10 \mathrm{cc}$ syringe and then spun down at $250 \mathrm{~g}$ for $10 \mathrm{~min}$. After the supernatant was decanted, each pellet was briefly resuspended with $1 \mathrm{ml}$ sterile $\mathrm{ddH}_{2} \mathrm{O}$ to lyse red blood cells and then recentrifuged. Cell pellets were resuspended in $5 \mathrm{ml}$ complete media and passed through a $70 \mu \mathrm{m}$ cell strainer. Cells were then counted using a Beckman Coulter counter. Cytospins were made by centrifuging 50000 cells onto microscope slides using a Shandon Cytospin. The slides were allowed to airdry and then stained with Diff-Quick Solution (Baxter Scientific, Deerfield, IL, USA). Slides were rinsed in water and allowed to air-dry. A total of 200 cells were counted from four randomly chosen high-power microscope fields for each sample. The differential percentage was multiplied by the total leucocyte number to derive the absolute number of monocyte/macrophages, polymorphonuclear cells (PMNs), lymphocytes and eosinophils per sample.

\section{$\mathrm{CD} 4^{+} \mathrm{T}$ cell depletion and flow cytometric sorting of $\mathrm{CD}_{11 b^{+} \text {myeloid cells }}$}

On the same day, tetracycline-containing TestDiet was provided to the mice, and $1 \mathrm{mg}$ of anti-CD4 antibody was injected i.p. into mice. Twenty-four $h$ and 11 days postantibody injection, red blood cell lysis was performed to isolate and stain whole blood cells with fluorescein isothiocyanate (FITC)-labelled anti-CD3 and phycoerythrin (PE)labelled anti-CD4 antibodies. Stained cells were washed and fixed with $1 \%$ paraformaldehyde overnight and kept in the dark at $4^{\circ} \mathrm{C}$ until analysis using a fluorescence activated cell sorter (FACS)Calibur flow cytometer (Becton Dickinson).

Half a million lung leucocytes in each test tube were used for antibody staining and flow cytometric sorting. After blocking non-specific binding with Fc blocker (BD Pharmingen, San Diego, USA), cells were stained with isotype control or FITC-labelled anti-CD11b (from Pharmingen). Stained cells were incubated at $4^{\circ} \mathrm{C}$ for $20 \mathrm{~min}$ and then washed twice with FACS buffer $[1 \times \mathrm{PBS}, 0 \cdot 2 \%$ bovine serum albumin (BSA), $0 \cdot 1 \%$ sodium azide] before sorting on a BD Biosciences FACSVantage SE Cell Sorter.

\section{Flow cytometry identification of IL-13-producing myeloid cells in the IL-10 OE mice lung}

Whole lung leucocytes were isolated from IL-10 OE mice given doxy chow for 11 days. Cells were treated with $50 \mathrm{ug} / \mathrm{ml}$ phorbol myristate acetate (PMA) and $1 \mathrm{ug} / \mathrm{ml}$ ionomycin in the presence of GolgiPlug and GolgiStop (BD Pharmingen) for $5 \mathrm{~h}$, spun down and resuspended in FACS buffer $(1 \times$ PBS, $0 \cdot 2 \%$ BSA, $0 \cdot 1 \%$ sodium azide $)$. After blocking non-specific binding with Fc blocker (BD Pharmingen), the following antibodies were used for examining cell surface marker expression: FITC-conjugated anti-CD11b (M1/70; BD Pharmingen); R-PE-conjugated anti-CD11c (HL-3; BD Pharmingen); PE-conjugated antiCD49b (DX5; eBiosciences, San Diego, CA, USA); PE conjugated Gr-1 (RB6-8C5; Biolegend, San Diego, CA, USA); and allophycocyanin (APC)-conjugated anti-F4/80 (BM8; Biolegend). The following isotype control antibodies were used for setting the myeloid cell gates: FITC-conjugated rat IgG2b $\kappa$ (BD Pharmingen); R-PE-conjugated Ham IgG1 $\lambda 1$ (BD Pharmingen); PE-conjugated Rat immunoglobulin 
(Ig)M (eBiosciences); PE-conjugated rat IgG2b $\kappa$ (Biolegend); and APC-conjugated rat IgG2a $\kappa$ (Biolegend). After surface marker staining, lung leucocytes were fixed and permeabilized with BD Cytofix/Cytoperm kit and then incubated with labelled anti-mouse IL-13 for $1 \mathrm{~h}$ at room temperature (RT). The following anti-mouse IL-13 antibodies and isotype controls were used: Alex 647-conjugated anti-IL-13(eBio 13A; eBiosciences); PE-conjugated anti-IL13(eBio 13A; eBiosciences); Alex 647-conjugated rat IgG1 $\kappa$ and PE-conjugated rat IgG1 $\kappa$ (eBiosciences). Positive staining of intracellular IL-13 was defined by comparing with isotype controls and analysed using the Accuri C6 sampler flow cytometer.

\section{Statistical analysis}

All statistics were performed using Graphpad Prism 4 (Graphpad, San Diego, CA, USA). Values were expressed as the mean \pm standard error of the mean. Significance was assigned for $P<0 \cdot 05$. Data sets were analysed using Student's $t$-test or one-way analysis of variance (ANOVA), with individual group means being compared with the StudentNewman-Keuls post-test.

\section{Results}

Effects of early IL-10 'turn on' on $\mathrm{RSV}$-induced inflammation

Previous studies with this clinical isolate of RSV in susceptible mice identified two distinct phases of lung inflammation, i.e. acute phase (within $24 \mathrm{~h}$, characterized in part by increased cytokine and CXC chemokine expression mediated via Toll-like receptor 3 activation) [24] and late phase (days 8-10 post-infection, characterized by Th2 cytokine production and increased mucus production and airway hyperactivity) $[18,25]$. Based on these previous studies, we examined the lungs of infected mice at both $24 \mathrm{~h}$ and 8 days post-RSV infections in the setting of lung-specific IL-10 OE. At $24 \mathrm{~h}$, the overall expression of chemokines [keratinocyte-derived chemokine (KC), monocyte chemoattractant protein (MCP)-1, macrophage inflammatory protein (MIP)-1 $\alpha$, inflammatory protein (IP)-10, MIP-2] and cytokines [IL-1 $\beta$, IL-6, IL-12 and interferon (IFN)- $\alpha$ ] was suppressed significantly in the IL-10 OE mice compared to TG- mice (Fig. 1a,b). Cox-2, another important mediator in RSV-induced lung pathology, was also inhibited
Fig. 1. Over-expression of interleukin (IL)-10 in the lung inhibited respiratory syncitial virus (RSV)-induced acute inflammation. Transgenic (TG)- and IL-10 over-expression (OE) mice were fed doxy chow 3 days prior to RSV infection. At $24 \mathrm{~h}$, mice lung were harvested and snap-frozen for protein and RNA isolation. Proteins extracted from lung tissue were analysed by multiplex assay (Bio-Rad). Protein values are reported as mean \pm standard error of the mean (s.e.m.) in pg/ml. RNA was isolated using the Trizol method and analysed by quantitative polymerase chain reaction (q-PCR) using specific primer/probe. All mRNA values are normalized to glyceraldehyde-3-phosphatedehydrogenase (GAPDH) expression and reported as the mean \pm s.e.m. fold-increase compared with the level detected in non-infected control mice. Mean values were determined from $n=6$ mice per experimental group. ${ }^{\star} P<0 \cdot 05$ and ${ }^{* *} P<0 \cdot 01$ compared to TG- RSV-infected mice. (a)
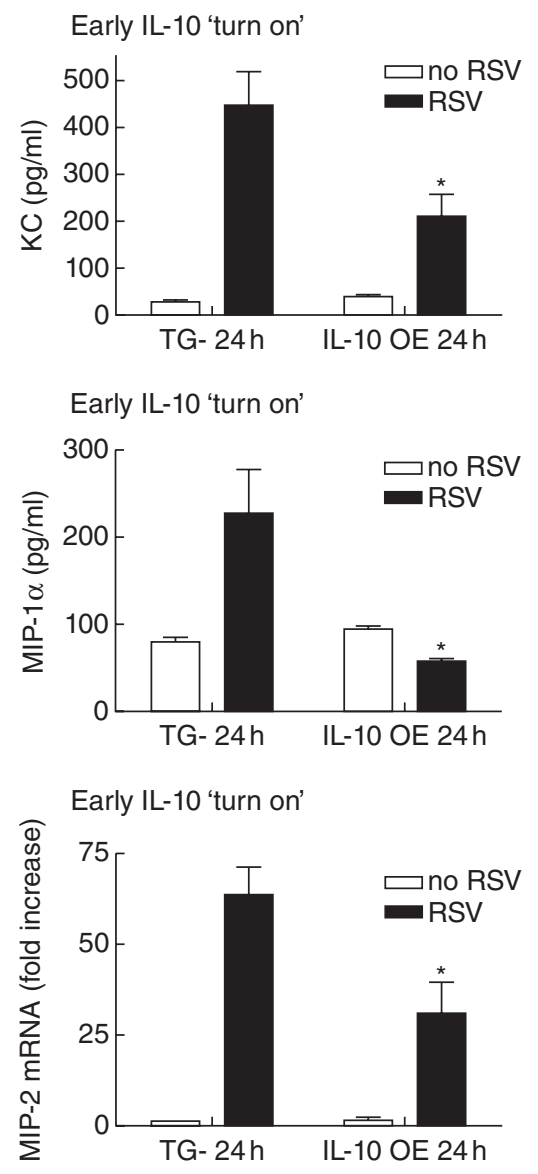

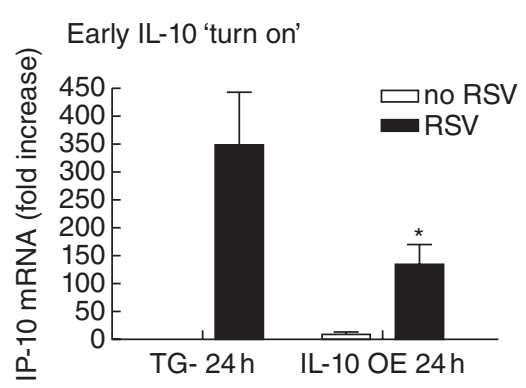

Early IL-10 'turn on'

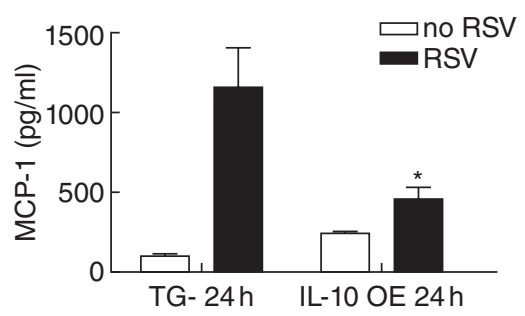

Early IL-10 'turn on'

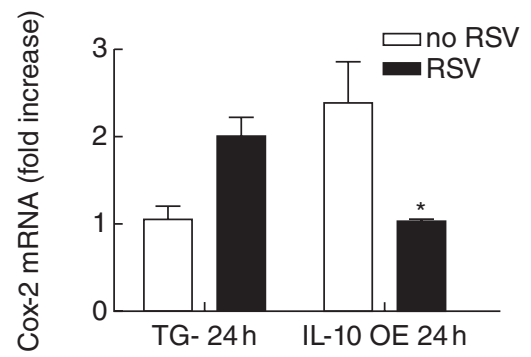


(b)

Early IL-10 ‘turn on'

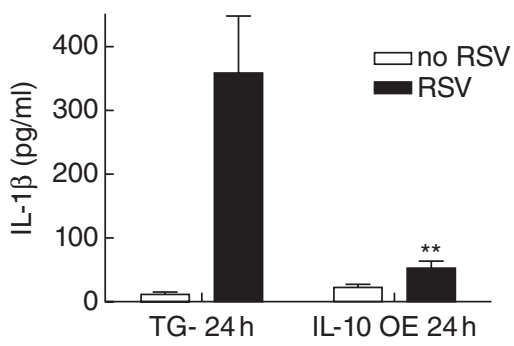

Early IL-10 ‘turn on'

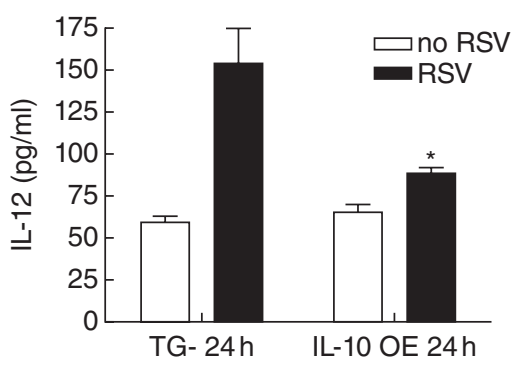

(c)

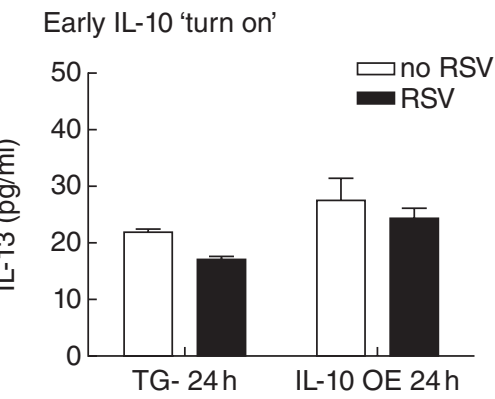

Early IL-10 'turn on'

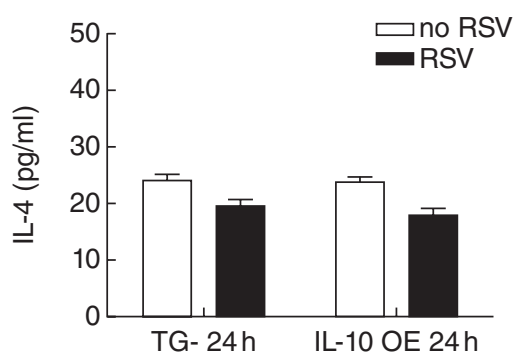

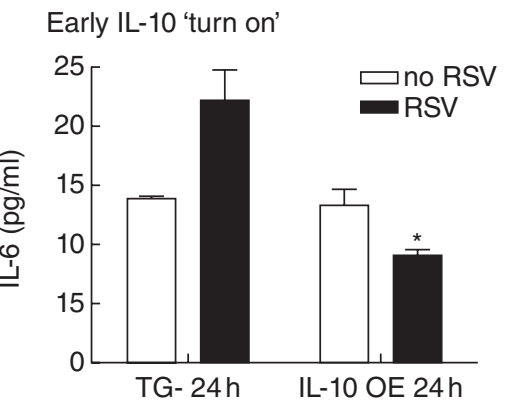

Early IL-10 'turn on'

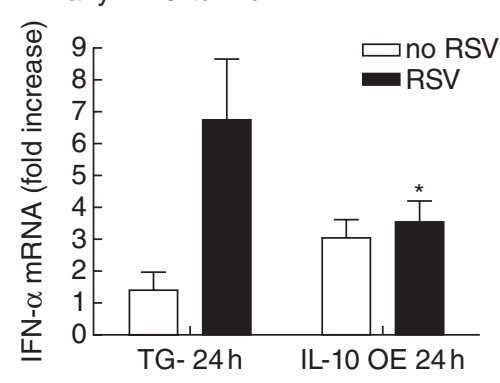

Early IL-10 'turn on'

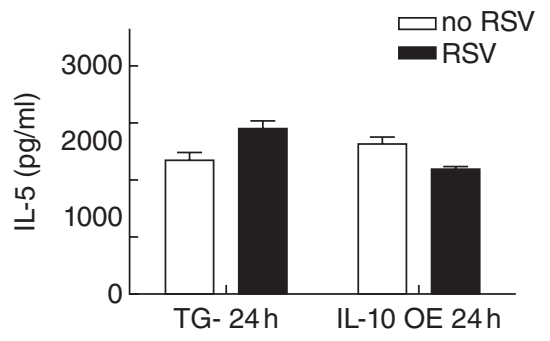

Fig. 1. Continued

(Fig. 1a). Of note, at $24 \mathrm{~h}$, Th2 cytokines were not induced significantly either by RSV infection or by IL-10 OE (Fig. 1c).

We next examined the effect of IL-10 OE at day 8 postRSV infection. We first measured endogenous mouse IL-10 and over-expressed human IL-10 levels by enzyme-linked immunosorbent assay (ELISA) to demonstrate that human IL-10, despite being over-expressed, did not induce significant changes of endogenous IL-10 expression. We observed that the over-expressed human IL-10 was about threefold higher than endogenous IL-10 in both non-infected and infected control mice (Fig. 2a). To determine the effects of IL-10 OE on the late phase of inflammation (i.e. day 8), we measured Th2-related chemokine (MCP-1), chemokine (C-C motif) ligand 3 (CCL3) and RANTES] [26,27] and Th1/Th2 cytokine (IFN- $\gamma$, IL-12/IL-13, IL-5 and IL-4) expression (Fig. 2b). Unexpectedly, we found that IL-10 OE alone (without RSV infection) induced overall highly up-regulated gene expression. For example, two of the most highly unregulated genes were MCP-1 and IL-13, and their 


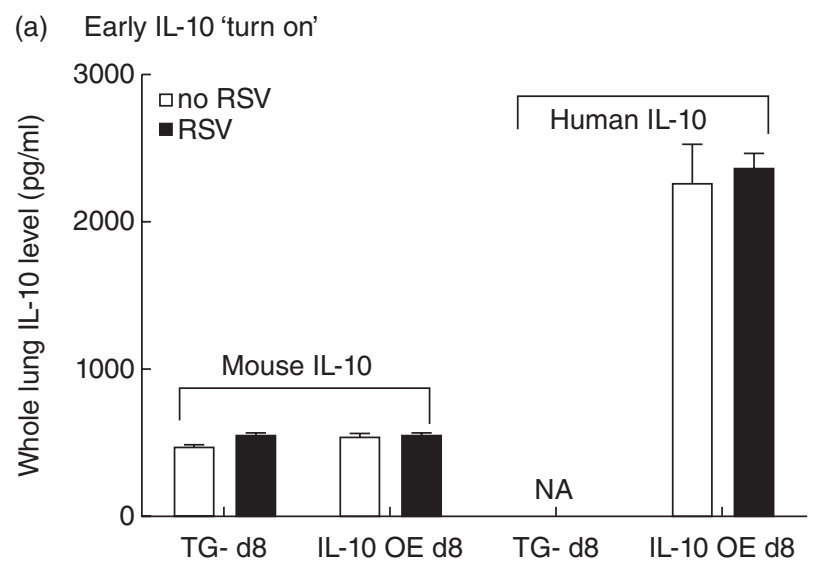

(b)
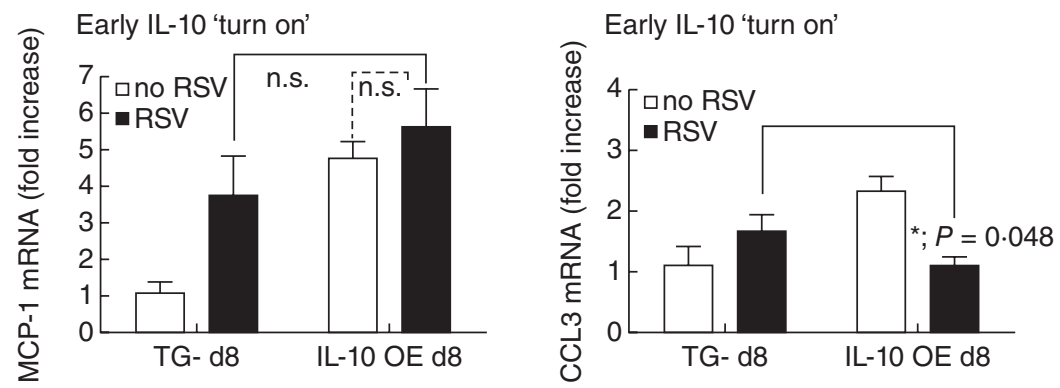

Early IL-10 'turn on'

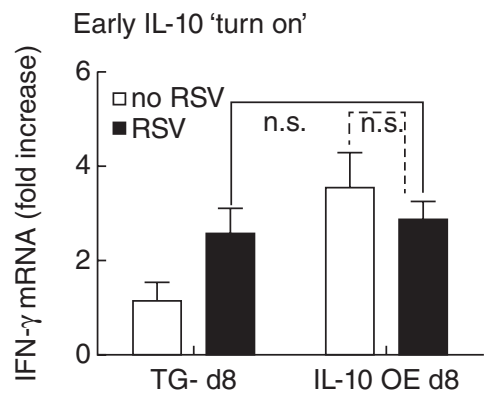

Early IL-10 'turn on'
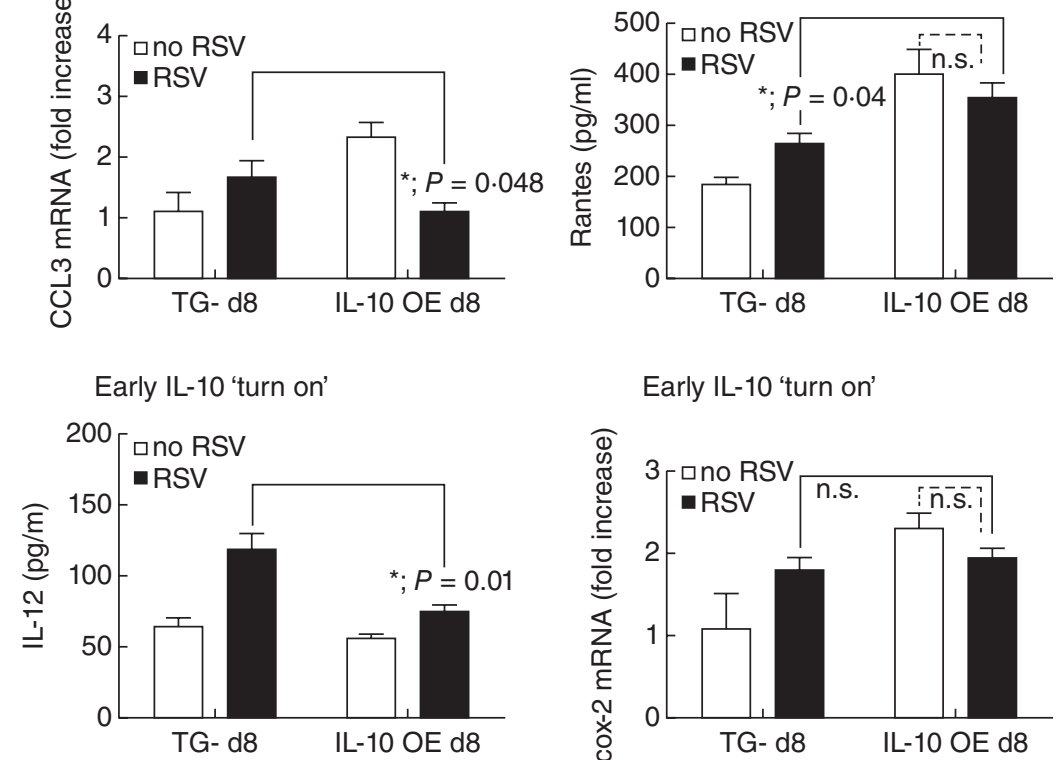

Early IL-10 'turn on'

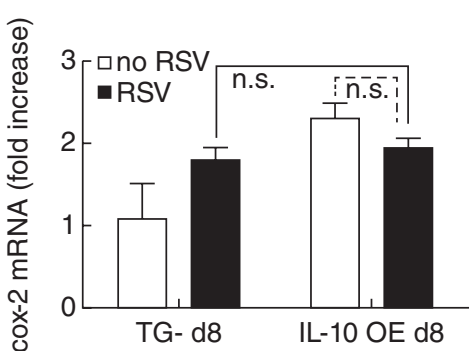

Early IL-10 'turn on'

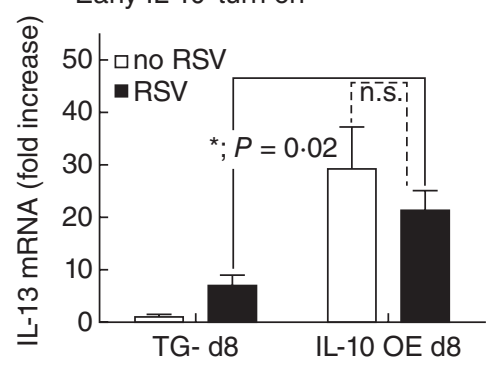

Early IL-10 'turn on'

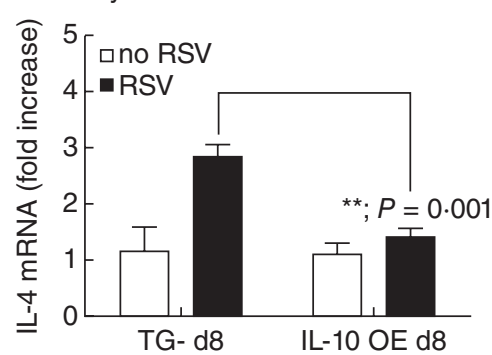

Early IL-10 'turn on'

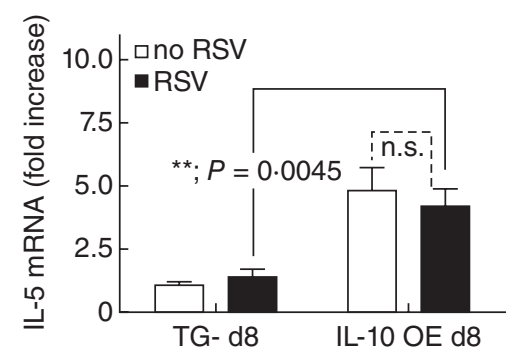

Fig. 2. Effects of early interleukin (IL)-10 'turn on' on respiratory syncitial virus (RSV)-induced T helper type 1 (Th1)/Th2 inflammation and viral clearance. Transgenic (TG)- and IL-10 over-expression (OE) mice were fed with doxy chow 3 days prior to RSV infection. At day 8, mice lung were harvested for protein and RNA isolation. Proteins extracted from lung tissue were analysed by multiplex assay (Bio-Rad). Protein values are reported as mean \pm standard error of the mean in $\mathrm{pg} / \mathrm{ml}$. RNA was isolated using the Trizol method and analysed by quantitative polymerase chain reaction (q-PCR) using specific primer/probe. All mRNA values are normalized to glyceraldehyde-3-phosphate-dehydrogenase (GAPDH) expression and reported as mean \pm standard error of the mean fold-increase compared with the level detected in non-infected control mice. (a) Whole lung IL-10 protein levels (mouse and human). (b) Whole lung chemokine and cytokine expression. (c) Whole lung mucus gene expression. (d) Q-PCR analysis of RSV surface protein $\mathrm{G}$ and nuclear protein $\mathrm{N}$ expression. Mean values were determined from $n=6-8$ mice per experimental group; n.s.: not significant. ${ }^{\star} P<0 \cdot 05$ and ${ }^{* *} P<0 \cdot 01$. 
(c)

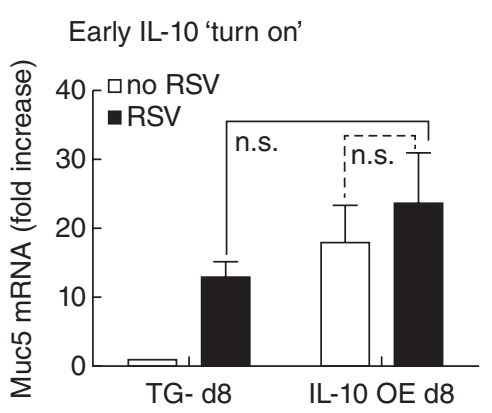

Early IL-10 'turn on'

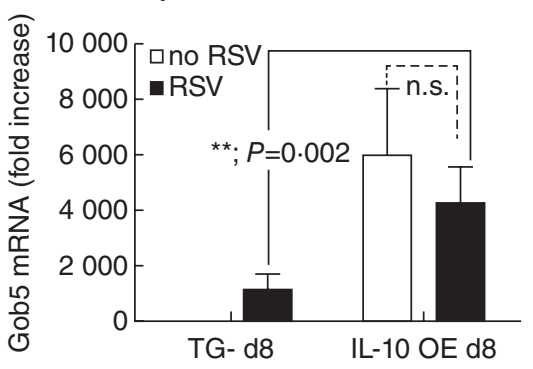

(d)

Early IL-10 'turn on'

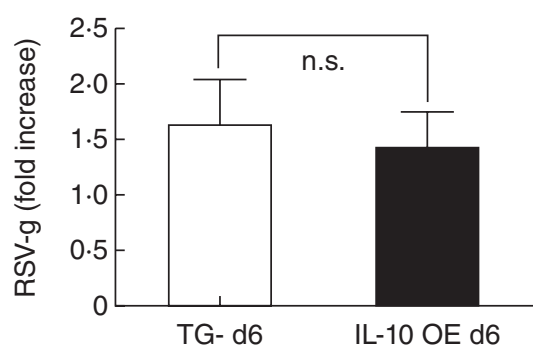

Early IL-10 'turn on'

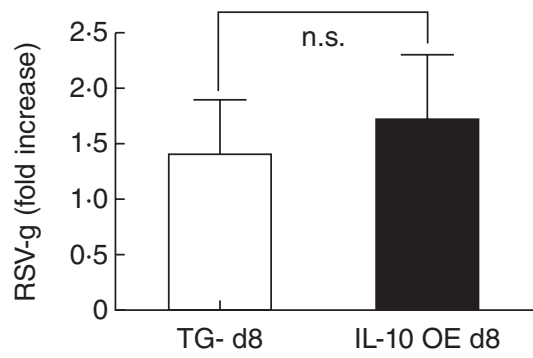

Early IL-10 'turn on'

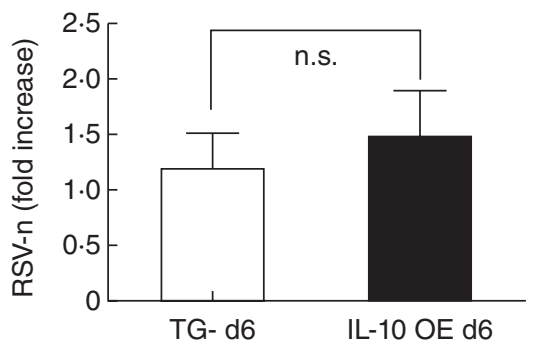

Early IL-10 'turn on'

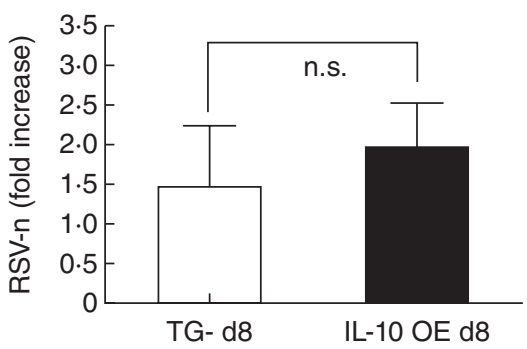

Fig. 2. Continued

expression levels were increased by $\sim 4 \cdot 5$-fold and $\sim 29$-fold, respectively, compared to the uninfected TG- group. CCL3, RANTES, IFN- $\gamma$, IL-5 and Cox- 2 were also up-regulated, albeit to a lesser degree (Fig. 2b). Conversely, IL-12 and IL-4 were not affected by IL-10 OE. As a result, in the early IL-10 'turn on' model, the IL-10 effects on RSV-induced late inflammation (day 8 post-RSV infection) were masked by the IL-10 alone effects, because the majority of the increased expression was attributed by IL-10 OE rather than RSV infection. Among the genes examined, we were able to detect changes of only IL-12, IL-4 and CCL3 gene expression. For these three genes, IL-10 OE suppressed significantly their expression induced by RSV infection $\left({ }^{*} P<0 \cdot 05\right)$.

In addition to chemokine and cytokine expression, mucus gene expression (Muc5 and Gob5) was also highly up-regulated by IL-10 OE alone after 8 days and this increased expression was not up-regulated or downregulated further following RSV infection (Fig. 2c). Again, IL-10 effects on RSV-induced mucus gene expression were masked by the highly up-regulated Muc5 and Gob5 expression in the no RSV group. We also examined the effects of early IL-10 'turn on' on viral clearance by quantitative-PCR (q-PCR) analysis on two RSV proteins, surface protein G and nuclear protein $\mathrm{N}$, at both days 6 and 8 post-infection (Fig. 2d). Results showed that no significant differences were detected between control mice and the IL-10 OE mice, indicating that although early IL-10 'turn on' altered the lung inflammatory milieu, it did not affect clearance of the virus.
Blocking endogenous IL-10 at the time of RSV infection enhanced RSV-induced Th2 responses and lung pathophysiology

Because of the IL-10 only effect, we aimed to distinguish further the IL-10 effects on RSV-induced Th2 responses by using an experimental approach of blocking endogenous IL-10 at the time of RSV infection to evaluate Th2 responses (Fig. 3). Anti-IL-10 blocking was performed as described previously [22]. Anti-IL-10 serum or nonimmune serum was injected i.p. into wild-type Fvb/n mice immediately after RSV intrachacheal injection. Blocking efficiency of endogenous IL-10 was examined at $24 \mathrm{~h}$ in non-infected mice and at day 8 in RSV-infected mice. At $24 \mathrm{~h}$, whole lung IL-10 levels decreased by approximately half, and at day 8, IL-10 levels in the blocking group remained significantly lower than in the control group (Fig. 3a). In this setting, at day 8 both Th2 response genes (IL-13, IL-5 and IL-4), Cox-2 (Fig. 3b) and mucus genes (Muc5 and Gob5; Fig. 3c) were up-regulated significantly in the blocking group. Furthermore, immunohistology analysis showed that the degree of PAS-staining and the severity of epithelial cell detachment in the anti-IL-10 blocking group were significantly higher than in the control group (Fig. 3d). Therefore, decreasing IL-10 levels at the time of RSV infection strongly intensified Th2 responses and pathological changes, which suggests strongly that early IL-10 expression regulates RSV-induced lung inflammation and pathophysiology negatively. 
(a)

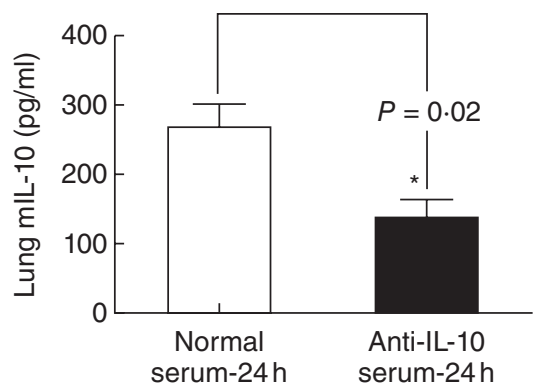

(b)

Fig. 3. Endogenous interleukin (IL)-10 blocking at the time of respiratory syncitial virus (RSV) infection-intensified T helper type 2 (Th2) responses and lung pathophysiology. Wild-type $\mathrm{Fvb} / \mathrm{n}$ mice were infected with $\sim 1 \times 10^{5}$ plaque-forming units ( $\mathrm{pfu}$ ) of RSV virus and injected intraperitoneally (i.p.) with normal serum or anti-IL-10 serum immediately after virus infection. At day 8 , mice lung were harvested for RNA isolation and lung section preparation. (a) Enzyme-linked immunosorbent assay (ELISA) measurement of whole lung IL-10 levels at $24 \mathrm{~h}$ and 8 days after anti-IL-10 blocking. (b) Quantitative polymerase chain reaction (q-PCR) analysis of cytokine gene expression at day 8 post-infection. (c) q-PCR analysis of mucus gene expression at day 8 post-infection. (d) Whole lung immunohistology analysis. Lung tissue sections were stained with haematoxylin and eosin (H\&E) for analysis of inflammatory cell accumulation and periodic acid-Schiff (PAS) for assessment of mucus production. Lung section preparation and staining were performed as described in Materials and methods. Final magnification $\times 100$. Sections were representative of $n=5-6$ mice per experimental group.
Anti-IL-10 blocking

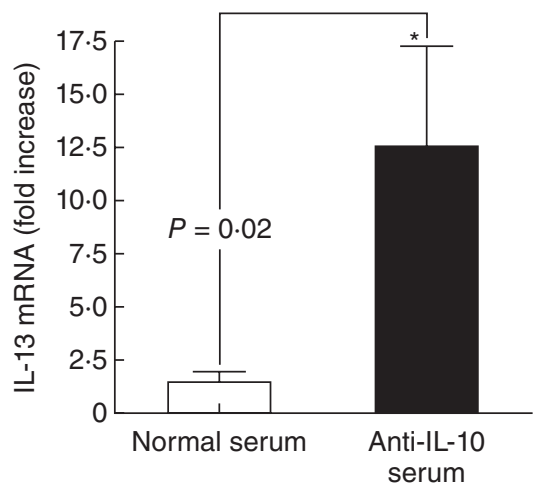

Anti-IL-10 blocking

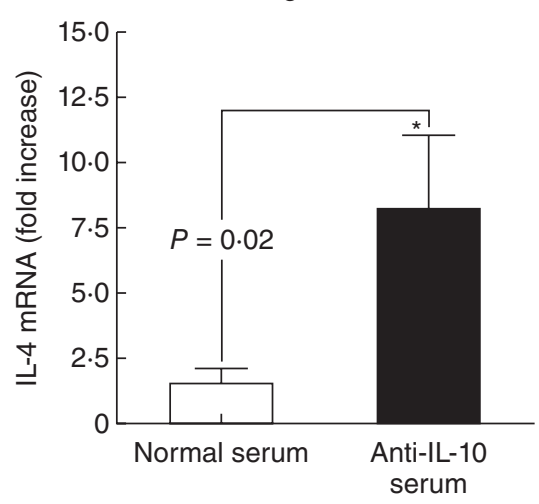

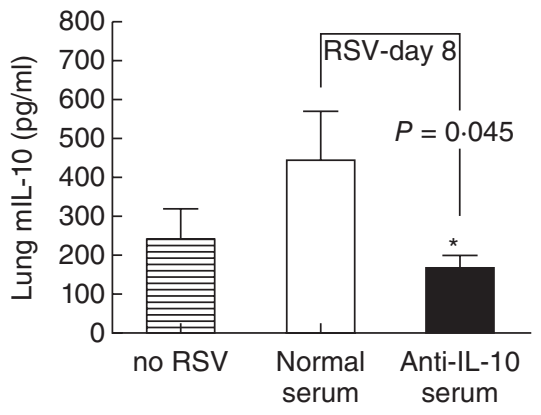

Anti-IL-10 blocking

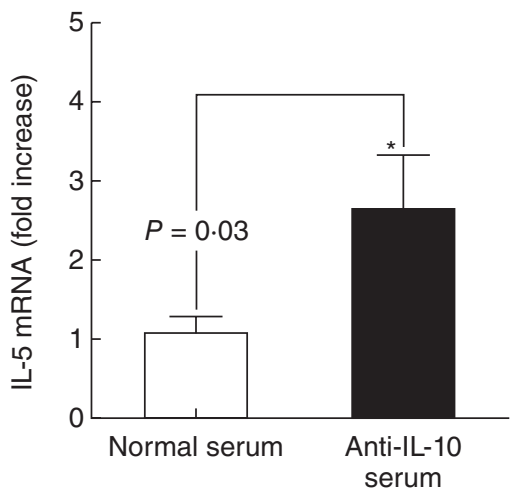

Anti-IL-10 blocking

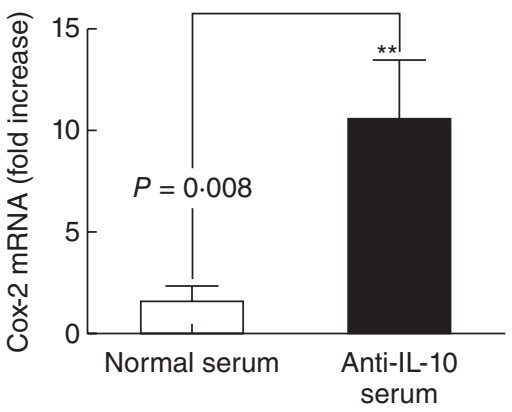

\section{OE of IL-10 increased leucocyte recruitment independently into the lung}

Because we found that IL-10 OE induced up-regulation of Th2-related chemokine expression (MCP-1, RANTES and CCL3, etc.) in the lung (Fig. 2b), we investigated the impact of these elevated chemokines on leucocyte recruitment. Immunohistology analysis consistently showed significantly increased cellular infiltration in the lungs of the IL-10 OE mice compared to mice not provided with doxy food (Fig. 4). At day 9 of doxy diet, a mononuclear cell infiltration along the peribronchial and perivascular areas was noted in the IL-10 OE mice, and modest mucus production (examined by positive PAS staining) was detected along the bronchial epithelials (middle panel). By day 11, cellular infiltration became more intensified and PAS staining of the lungs demonstrated both goblet cell hyperplasia and substantially increased mucus production (bottom panel). This was not seen in bitransgenic mice not provided with doxyspiked chow (upper panel). To investigate further the nature of the infiltrating cells, whole lung leucocytes were isolated from mice provided with access to doxy food for a similar time as in the above Fig. 1 experiment and subjected to differential counting analysis (Table 1). Our data indicated that IL-10 OE increased the total number of leucocytes in the lung by $\sim$ two-fold compared to the control TG- mice, with the majority of these cells being lymphocytes $(\sim 90 \%)$. While only $\sim 2-5 \%$ of the cells were monocytes, the total number was increased by $\sim 3-5$-fold. Although the total number of neutrophils in the IL-10 OE mice was not 
(c)

\section{Anti-IL-10 blocking}

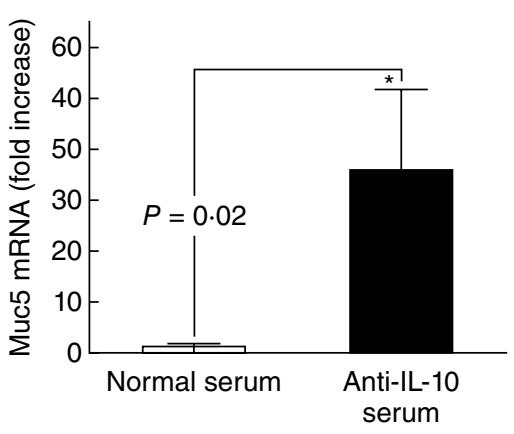

(d) Normal serum $\times 100)$

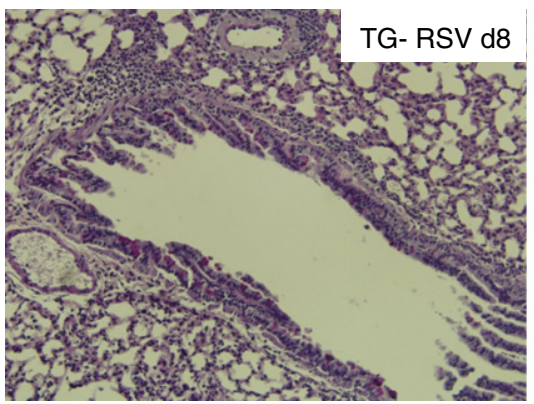

Anti-IL-10 blocking

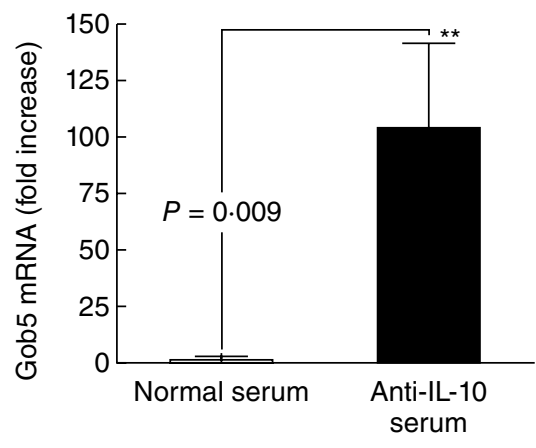

Anti-IL-10 serum

$\times 100)$

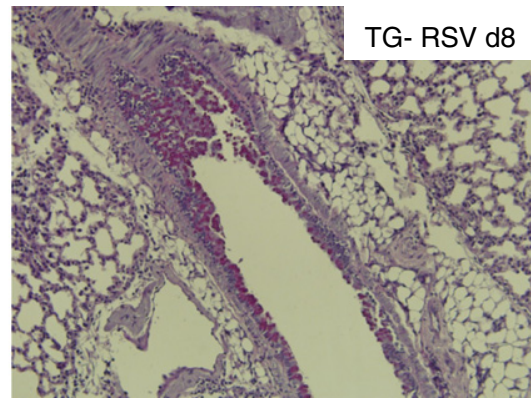

Fig. 3. Continued

ment, mice were given TestDiet 3 days prior to RSV infection, and Th2 cytokine expression was analysed at day 8 post-infection. The total duration of TestDiet treatment is 11 days. Therefore, we chose day 11 and examined the depletion efficiency by flow cytometry at both $24 \mathrm{~h}$ and day 11 post-anti-IL-10 injection. Approximately 95\% of $\mathrm{CD}^{+} \mathrm{T}$ cells were depleted from the OE mice (Fig. 5a). Of note, it has been shown to take $-3-4$ weeks for the depleted cells to repopulate [29]. At day 11, q-PCR analysis of whole lung RNA showed that $\mathrm{CD}^{+} \mathrm{T}$ cell depletion did not affect IL-13 and mucus gene expression (Fig. 5b). Thus, these data indicated that IL-10-induced IL-13 production was from cell populations other than $\mathrm{CD}^{+} \mathrm{T}$ cells. It was reported recently that myeloid cells also produce IL-13 [30-32]. Thus, to examine whether myeloid cells in IL-10 OE induced IL-13 production in our model, we harvested whole lung leucocytes and sorted $\mathrm{CD}_{11} \mathrm{~b}^{+}$cells and analysed IL-13 expression by q-PCR. Significantly increased IL-13 expression was detected from CD11 $\mathrm{b}^{+}$cells sorted from IL-10 OE compared to the control TG- group (Fig. 5c). injected i.p. into IL-10 OE mice. In the above Fig. 2 experi-

Table 1. Differential leucocyte numbers in the lung following days of doxy chow treatment $\left(\times 10^{6}\right)$.

\begin{tabular}{|c|c|c|c|c|c|c|c|c|c|c|}
\hline \multirow[b]{2}{*}{ Day } & \multicolumn{2}{|c|}{ Total cells } & \multicolumn{2}{|c|}{ PMN } & \multicolumn{2}{|c|}{ Lymphocyte } & \multicolumn{2}{|c|}{ Monocyte } & \multicolumn{2}{|c|}{ Eosinophil } \\
\hline & TG- & IL-10 OE & TG- & IL-10 OE & TG- & IL-10 OE & TG- & IL-10 OE & TG- & IL-10 OE \\
\hline 9 & $11 \cdot 15 \pm 0.67$ & $19 \cdot 36 \pm 2 \cdot 64$ & $2 \cdot 10 \pm 0 \cdot 15$ & $1.57 \pm 0.27$ & $9 \cdot 20 \pm 0 \cdot 86$ & $16 \cdot 57 \pm 2 \cdot 86$ & $0 \cdot 2 \pm 0.08$ & $1 \cdot 04 \pm 0 \cdot 44$ & $\mathrm{ND}$ & $0 \cdot 31 \pm 0 \cdot 07$ \\
\hline 14 & $10.64 \pm 0.57$ & $26 \cdot 00 \pm 4.00$ & $3.72 \pm 0.42$ & $4.87 \pm 1 \cdot 13$ & $6 \cdot 25 \pm 0 \cdot 25$ & $19 \cdot 23 \pm 2 \cdot 07$ & $0.48 \pm 0.08$ & $1.23 \pm 0.57$ & ND & $0.39 \pm 0.07$ \\
\hline
\end{tabular}

Number of differentials $=$ percentage of differentials $\times$ total lung leucocyte number. TG-: transgenic; IL: interleukin; OE: over-expression; PMN: polymorphonuclear cells. 

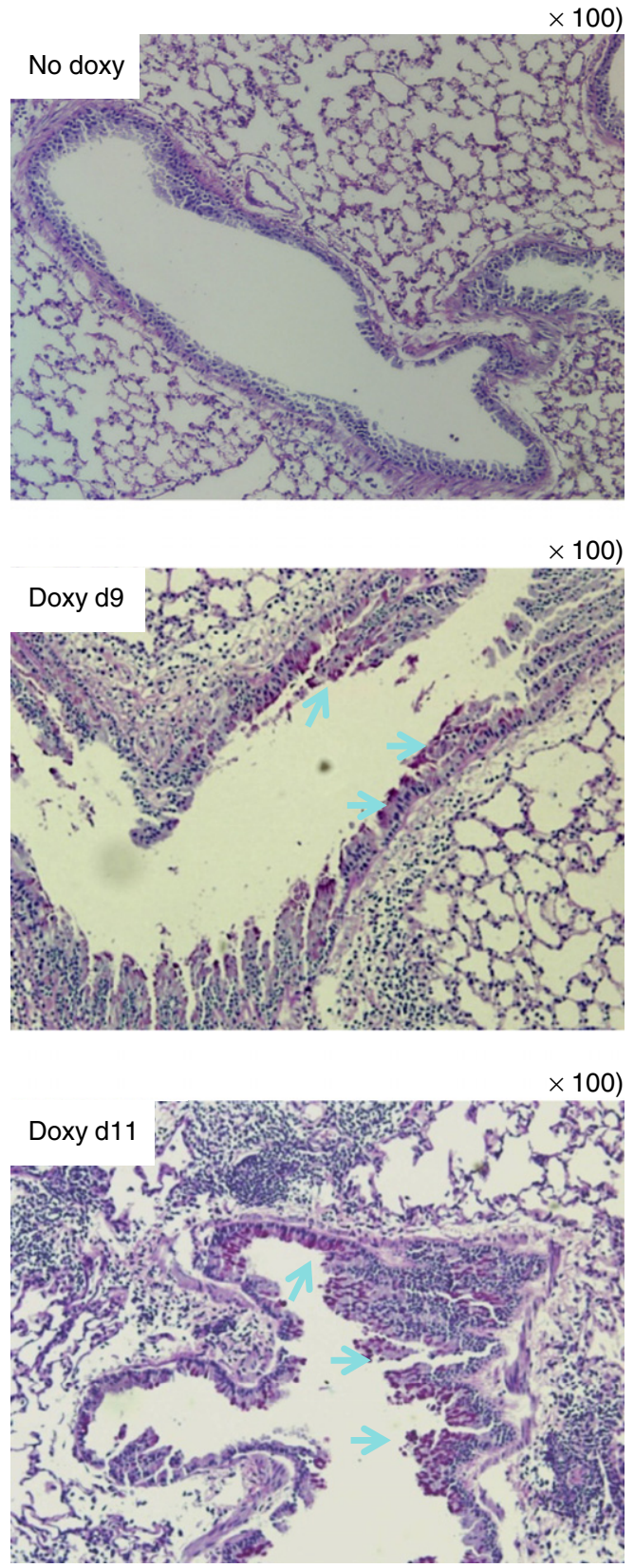

Fig. 4. Lung immunohistology change induced by the over-expression (OE) of interleukin (IL)-10. IL-10 OE mice were fed with TestDiet (doxycycline-containing chow) for 9 and 11 consecutive days. Lung section preparation and staining were performed as described in Fig. 3. Final magnification $\times 100$. Sections are representative of $n=6$ mice per group.

\section{Flow cytometry characterization of IL-13-producing myeloid cells}

To characterize further the source of IL-13-producing myeloid cells, whole lung leucocytes isolated from IL-10 OE mice (doxy day 11) were stained with different surface markers for myeloid subtypes and analysed for intracellular
IL-13 expression by flow cytometry. As shown in Fig. 6, fluorescence-labelled isotype controls were used for setting the gates for dendritic cells $\left(\mathrm{CD}_{11} \mathrm{~b}^{+} / \mathrm{CD} 11 \mathrm{c}^{+}\right.$; Fig. $\left.6 \mathrm{a}\right)$, natural killer (NK) cells $\left(\mathrm{CD} 11 \mathrm{~b}^{+} / \mathrm{CD}_{4} \mathrm{gb}^{+}\right.$; Fig. $\left.6 \mathrm{~b}\right)$, macrophages $\left(\mathrm{CD} 11 \mathrm{~b}^{+} / \mathrm{F} 4 / 80^{+}\right.$; Fig. $\left.6 \mathrm{c}\right)$ and neutrophils $\left(\mathrm{CD}_{11 \mathrm{~b}^{+} /}\right.$ Gr- $1^{+}$; Fig. 6d) [33-35]. By comparing the fluorescence shift of intracellular IL-13 staining and isotype control staining (right panel), our analysis indicates that IL-13 was produced by dendritic cells and natural killer cells, but not macrophages or neutrophils. Taken together, we conclude that a subset of myeloid cells with the phenotype of $\mathrm{CD}_{11} \mathrm{~b}^{+} \mathrm{CD} 11 \mathrm{c}^{+} \mathrm{CD} 49 \mathrm{~b}^{+} \mathrm{Gr}-1^{-} \mathrm{F} 4 / 80^{-}$is the cellular source of IL-13 production in the IL-10 OE mice.

\section{Late IL-10 'turn on' promoted RSV-induced Th2 responses}

Previous studies with RSV A strain have delineated distinct stages of inflammation following virus infection, which are characterized as early phase and late phase [36]. In characterizing the expression of IL-10 in these phases we detected high IL-10 expression at day 6, which then gradually decayed at day 8 following RSV infection (Fig. 7a). Given the clinical observation that elevated IL-10 levels in patients during the late phases of RSV infection are associated with airway bronchoconstriction [13], we surmise that overexpressing IL-10 during the late phase of RSV-infection would have a different immune regulatory effect from that over-expressing IL-10 prior to the RSV infection. Therefore, we gave the animals doxy chow 2 days after RSV infection and examined Th2 cytokines, Th2-related chemokines and mucus gene expression at day 8 post-RSV infection (Fig. 7b,c). IL-10 OE-induced gene up-regulation was still detected, albeit to a lesser degree (TG- noRSV versus IL-10 OE noRSV). With RSV infection, a further increased chemokine (MCP-1, RANTES) and cytokine (IL-13, IL-5) gene expression were detected (IL-10 OE noRSV versus IL-10 OE RSV; $P<0 \cdot 05)$. Similar effects were observed on mucus gene expression (Fig. 7c). Therefore, in contrast to the inhibitory effects of IL-10 on RSV-induced inflammation observed in the above experiment (Figs 1-3), an additive effect was seen in this late IL-10 'turn on' model (i.e. TGRSV versus IL-10 OE RSV). Histopathology of the lungs in the IL-10 OE with RSV infection was also enhanced compared to the infected TG- mice (Fig. 7d). q-PCR analysis on RSV-g and RSV-n protein gene expression showed similar expression levels between control mice and IL-10 OE mice, indicating that late IL-10 'turn on' enhanced Th2 responses but did not affect viral clearance (Fig. 7e).

\section{Discussion}

To elucidate the varied roles of IL-10 in regulating pathogen-induced immune responses, our laboratory established a transgenic mouse model capable of inducible, lung- 
(a)

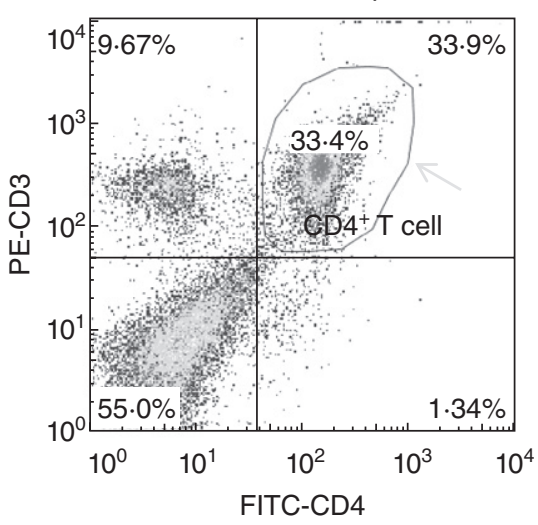

(b)

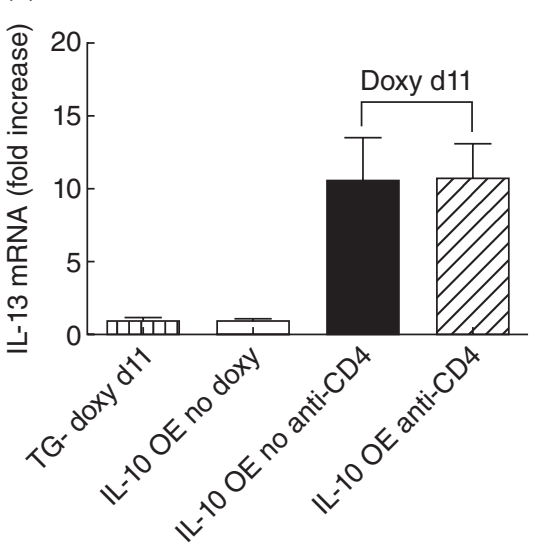

(c)

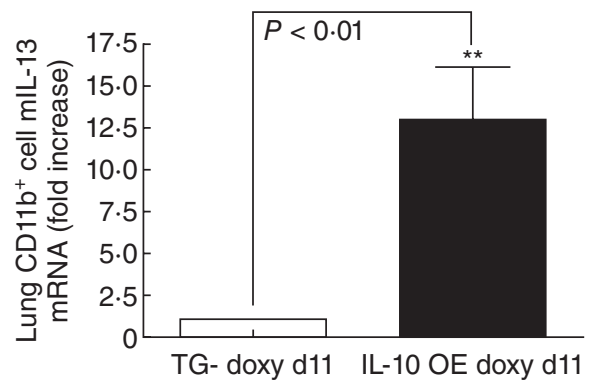

Day 1 post-CD4 ${ }^{+} \mathrm{T}$ depletion
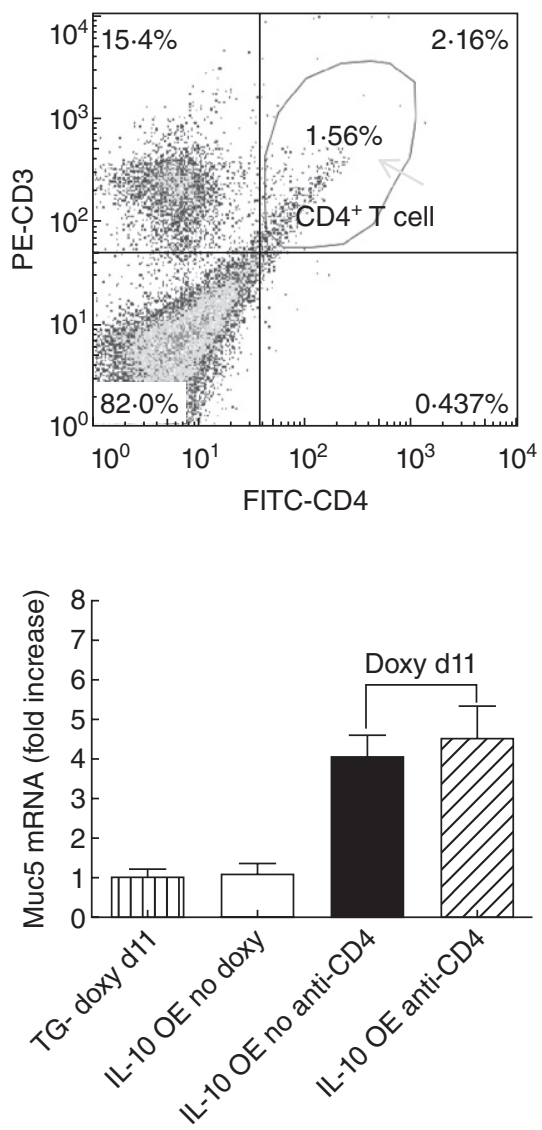

Day 11 post-CD4 ${ }^{+} \mathrm{T}$ depletion
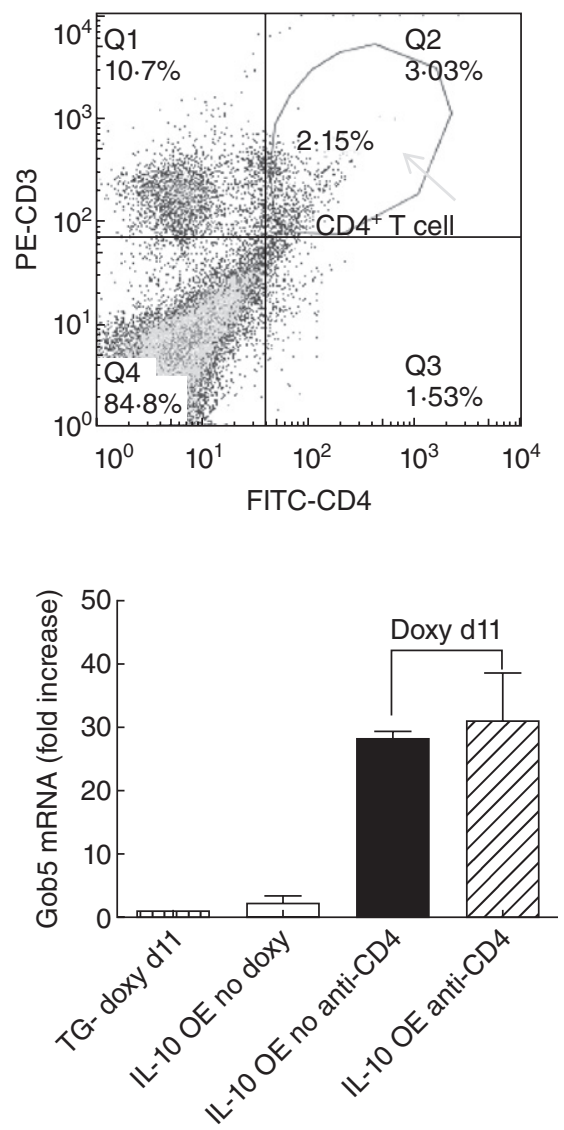

Fig. 5. $\mathrm{CD} 4^{+} \mathrm{T}$ cell depletion and $\mathrm{CD} 11 \mathrm{~b}^{+}$cell sorting. On the same day as introducing TestDiet to the animals, 1 mg of anti-CD4 antibody was injected intraperitoneally (i.p.) into interleukin (IL)-10 over-expression (OE) mice. Mice that were not injected with depletion antibody were used as controls. (a) Examination of $\mathrm{CD} 4^{+} \mathrm{T}$ cell depletion by flow analysis. The efficiency of $\mathrm{CD} 4^{+} \mathrm{T}$ cell depletion was analysed by flow at $24 \mathrm{~h}$ and day 11 after antibody injection. Whole blood isolation and staining are described in Materials and methods and $\mathrm{CD} 4^{+} \mathrm{T}$ cells were visualized as fluorescein isothiocyanate (FITC)-CD3 and phycoerythrin (PE)-CD4 double-positive cells on the flowchart. (b) CD4 $4^{+}$cell depletion did not affect IL-10 OE-induced IL-13 and mucus gene expression. Whole lung RNA was analysed at day 11 post-antibody injection. (c) Cell sorting of whole lung

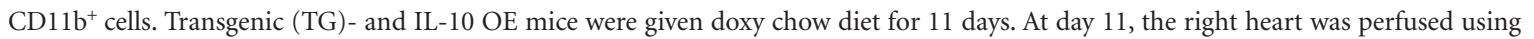
phosphate-buffered saline (PBS) and whole lung leucocytes were isolated using the collagenase method as described in Materials and methods. $\mathrm{CD}_{11} \mathrm{~b}^{+}$myeloid cells were sorted by flow cytometer. Total RNA was extracted using the Trizol method and expression of IL-13 and mucus genes were evaluated by quantitative polymerase chain reaction (q-PCR). Mean values were determined from $n=5$ mice per experimental group.

specific IL-10 OE [17]. Given the frequent reports of elevated IL-10 levels in children with severe lower respiratory tract viral infections and this cohort's predisposition to developing asthma, we aimed to elucidate the complex regulatory role of IL-10 in viral-induced lung inflammation using this transgenic mouse model. Our study demonstrated that if IL-10 is present at the time of RSV infection, it plays an overall anti-inflammatory role. IL-10 inhibits not 
(a)

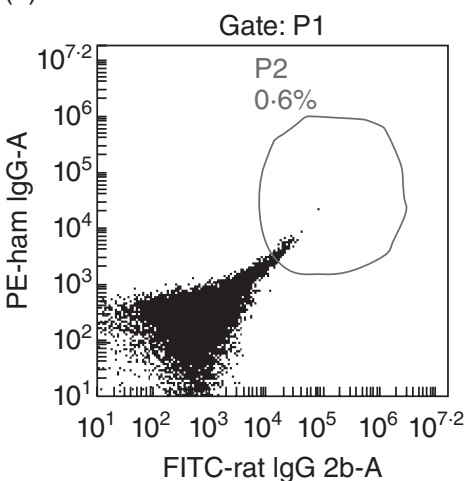

(b)

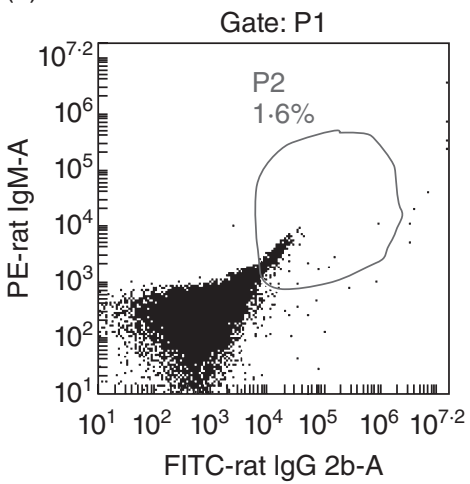

(c)

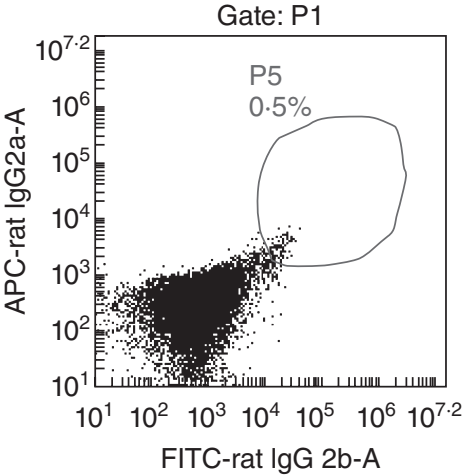

(d)

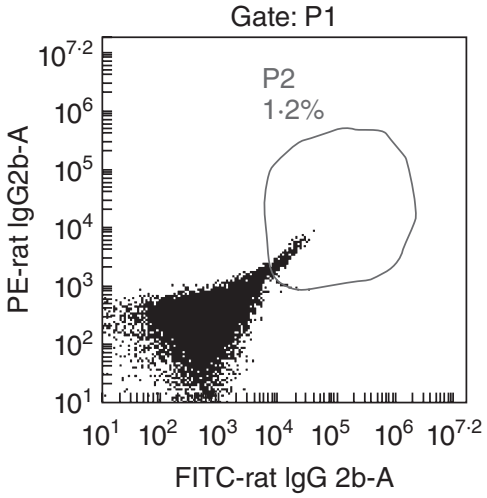

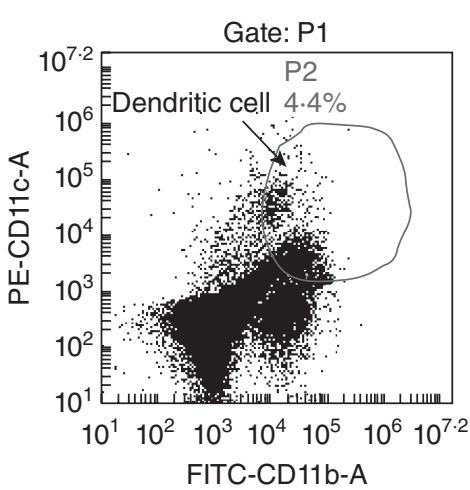
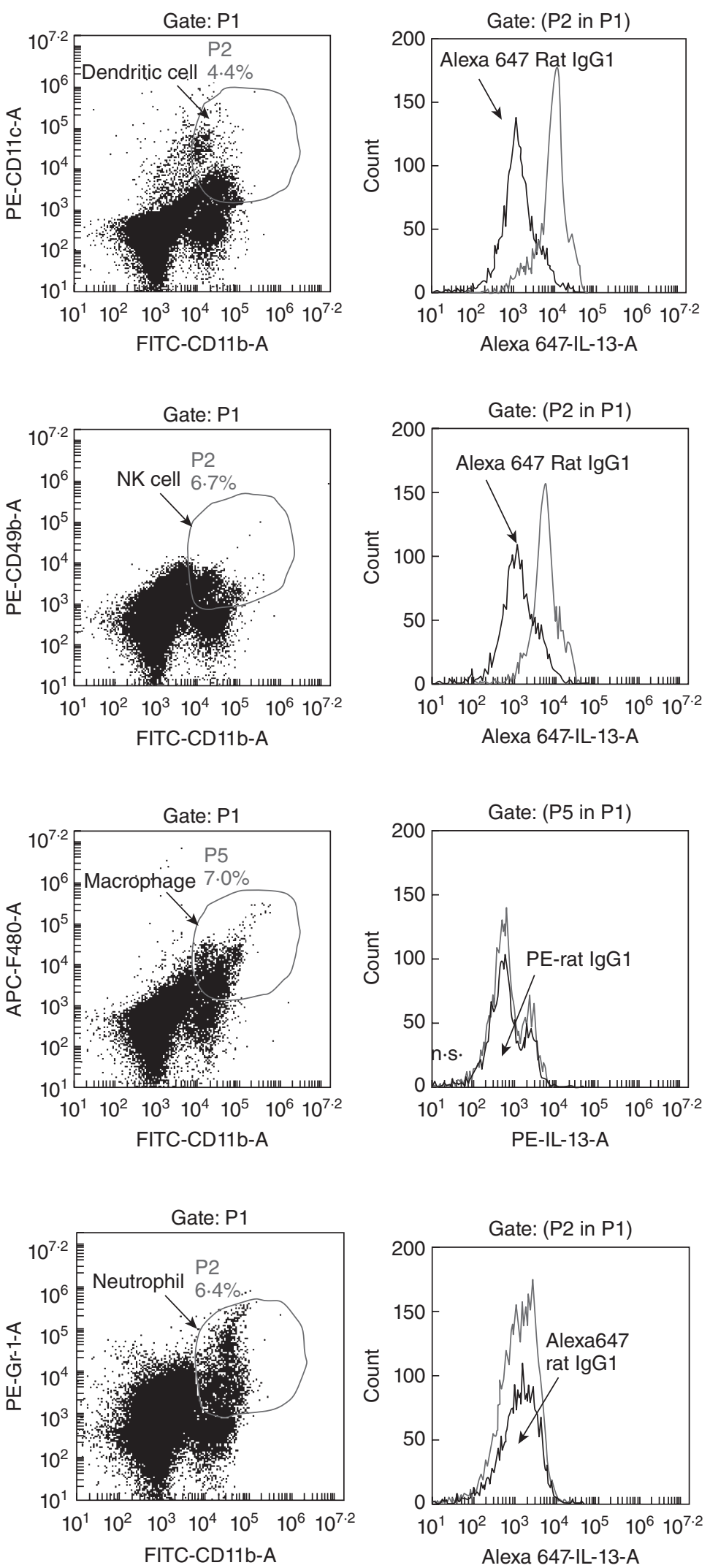
Fig. 6. Flow cytometry identification of interleukin (IL)-13-producing myeloid cells in the IL-10 over-expression (OE) mice lung. Whole lung myeloid cell subsets were identified by specific cell surface markers: dendritic cells $\left(\mathrm{CD} 11 \mathrm{~b}^{+} \mathrm{CD} 11 \mathrm{c}^{+}\right)$; natural killer cells $\left(\mathrm{CD} 11 \mathrm{~b}^{+} / \mathrm{CD} 49 \mathrm{~b}^{+}\right)$; macrophages $\left(\mathrm{CD} 11 \mathrm{~b}^{+} / \mathrm{F} 4 / 80^{+}\right)$and neutrophils $\left(\mathrm{CD} 11 \mathrm{~b}^{+} / \mathrm{Gr}-1^{+}\right)$. Fluorescence-labelled isotype controls were used to set the gates of myeloid subsets (left panel and middle panel). Intracellular expression of IL-13 was determined by comparing the fluorescence shift of anti-IL-13-stained cells and isotype control stained cells (right panel) and analysed on the Accuri C6 sampler flow cytometer. IL-13-producing cells are characterized as $\mathrm{CD} 11 \mathrm{~b}^{+} \mathrm{CD} 11 \mathrm{c}^{+} \mathrm{CD} 49 \mathrm{~b}^{+} \mathrm{F} 4 / 80^{-} \mathrm{Gr}-1^{-}$. Flow data are representative of two to three independent experiments.

Fig. 7. Late interleukin (IL)-10 'turn on' promoted respiratory syncitial virus (RSV)-induced inflammation without affecting viral clearance. (a) Quantitative polymerase chain reaction (q-PCR) analysis on endogenous IL-10 expression during the course of RSV infection. Mice lungs were harvested at days 1, 6 and 8 post-infection and analysed for endogenous IL-10 expression by q-PCR. (b-d) Both control and IL-10 over-expression (OE) mice were infected with $\sim 1 \times 10^{5}$ plaque-forming units (pfu) of RSV virus. Two days later, animals were switched to doxy chow and mice lungs were harvested at day 8 post-RSV. Whole lung protein and total RNA isolation were performed as described in Fig. 1. Lung cytokine, chemokine and mucus gene expression were analysed by q-PCR and bio-plex for regulated upon activation normal $\mathrm{T}$ cell expressed and secreted (RANTES) in (b) and (c). In (d), lung pathology was examined by staining with haematoxylin and eosin (H\&E) for analysis of inflammatory cell accumulation and periodic acid-Schiff (PAS) for assessment of mucus production. Final magnification $\times 100$. (e) q-PCR analysis on RSV surface protein G and nuclear protein $\mathrm{N}$ gene expression. Mean values were determined from $n=6-8$ mice per experimental group.

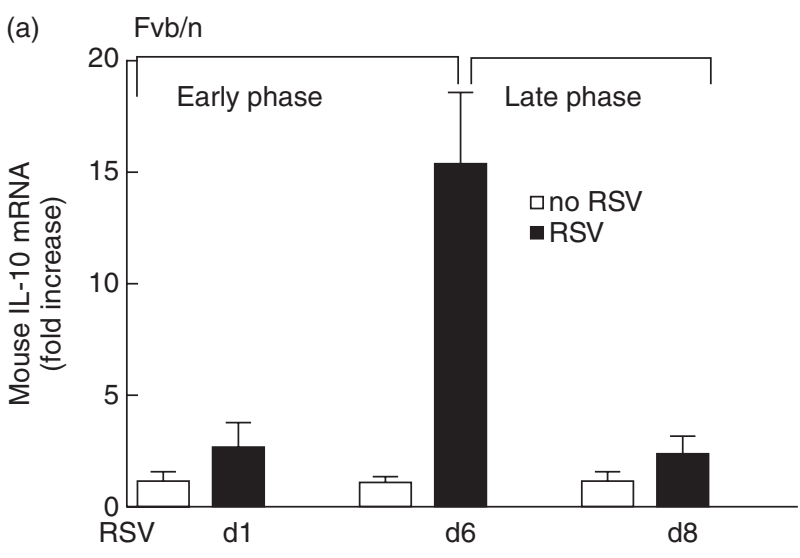

(b)
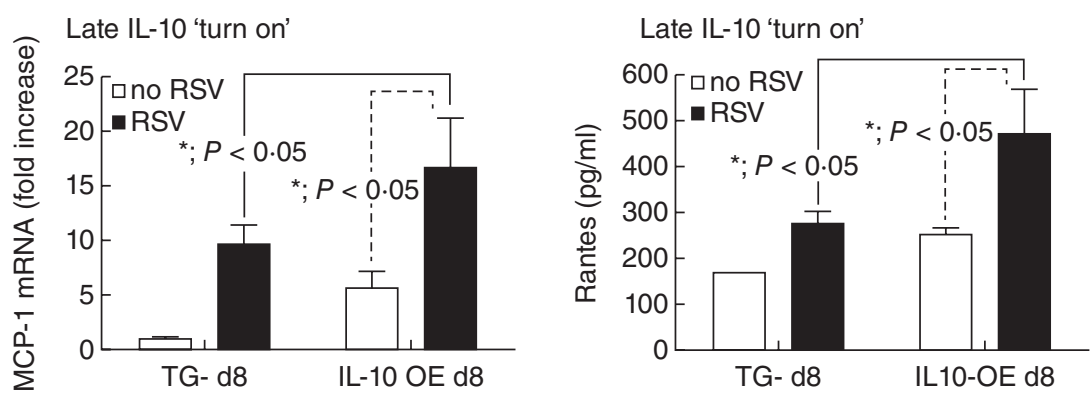

Late IL-10 'turn on'

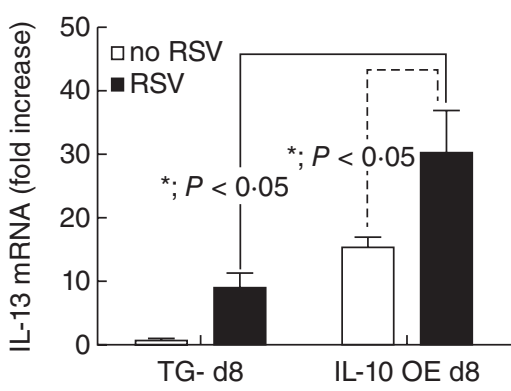

Late IL-10 'turn on'

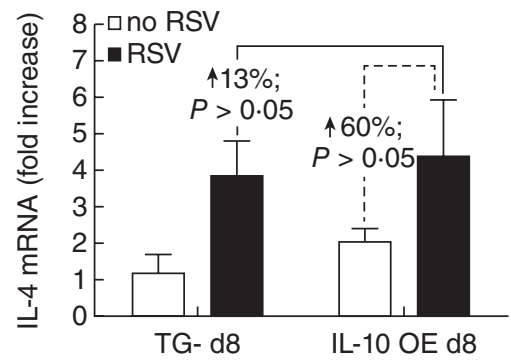

Late IL-10 'turn on'

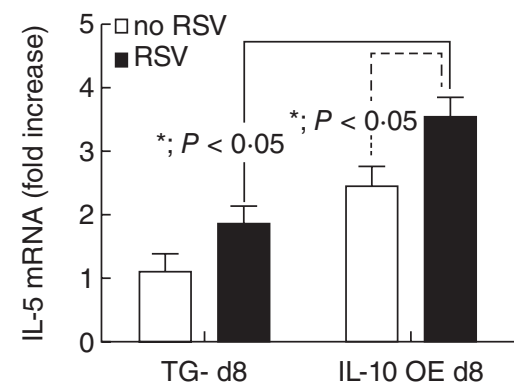

Late IL-10 'turn on'

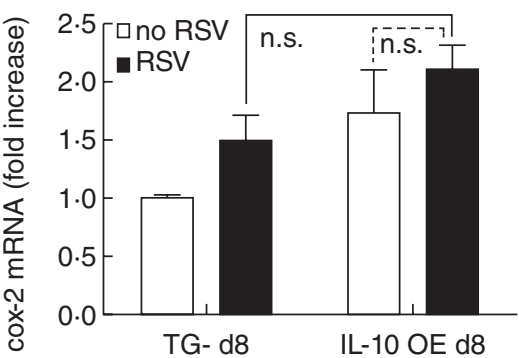


(c) Late IL-10 'turn on'

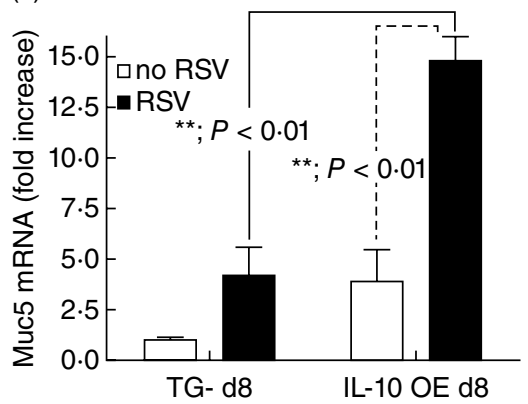

(d) Late IL-10 'turn on' $\times 100$ )

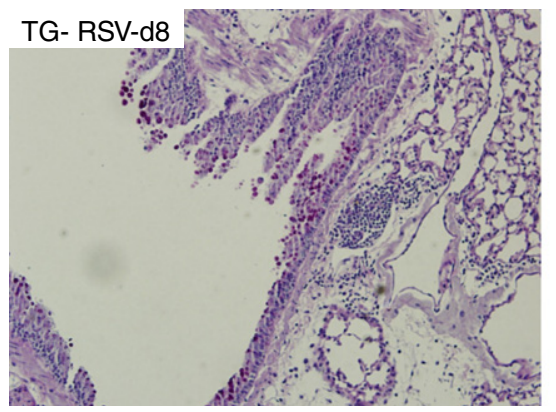

(e)

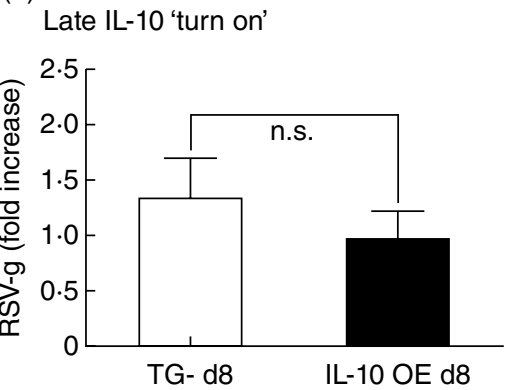

Late IL-10 'turn on'

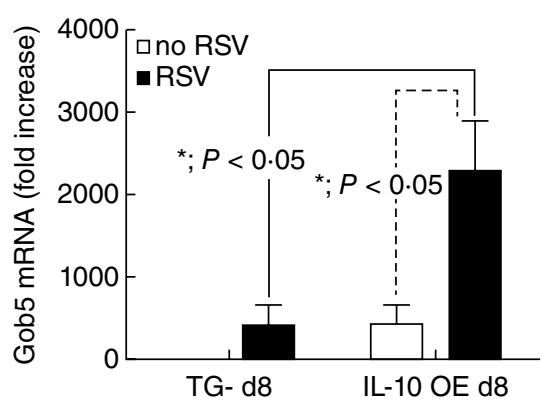

Late IL-10 'turn on' $\times 100$ )

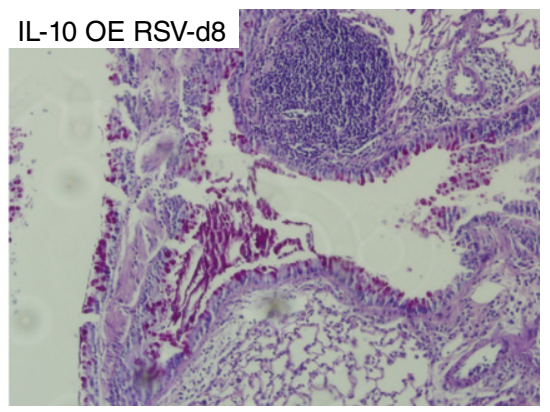

Late IL-10 'turn on'

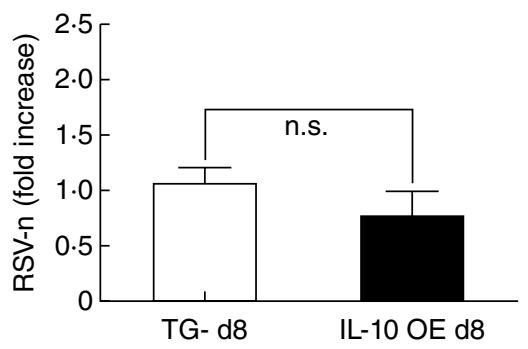

Fig. 7. Continued

only acute inflammation but also RSV-triggered late Th1/ Th2 responses. Contradictory to the anti-inflammatory role against virus infection, our data also showed that IL-10 OE alone altered substantially the histological appearance of the lung characterized by significantly increased mononuclear cell infiltration, goblet cell hyperplasia and mucus production. Further characterization of the infiltrating cells indicated $\mathrm{T}$ cell predominance which correlated with the up-regulation of Th2-related chemokines (MCP-1, RANTES and CCL3), known to mediate lymphocyte and eosinophil chemotaxis in the lung [37-40]. Importantly, we observed highly up-regulated IL-13 expression and moderately increased IL-5 in the IL-10 OE mice, indicating that IL-10 OE is independently capable of inducing a Th2predominant environment in the lung in the absence of a pathogen. These findings were somewhat surprising, given the commonly described inhibitory effect on chemokine expression attributed to IL-10 in acute lung injury [41]. Conversely, it also indicated the dual roles of IL-10 in modulating inflammation.
It has been demonstrated in murine RSV models that RSV-specific $\mathrm{CD}^{+}$and $\mathrm{CD}^{+}$effector $\mathrm{T}$ cells are key contributors to the development of asthmatic responses $[27,42,43]$. More recently, it has also been reported that regulatory $\mathrm{T}$ cells suppress airway hyperresponsiveness and tissue remodelling by secretion of IL-10 [44]. Under these conditions, IL-10 appears to be a negative regulator against viral-specific effector $\mathrm{T}$ cell responses $[42,45]$. The specificity of IL-10 effects on antigen-specific T cell activities was also demonstrated in other allergic models. For example, Zuany-Amorim showed that ovalbumin (OVA)-induced eosinophilic airway inflammation was decreased by co-administration of recombinant mIL-10 and antigen [46]. Moreover, Nakagome et al. found that IL-10 suppressed Th2 cytokine production only from $\mathrm{CD}^{+} \mathrm{T}$ cells that were restimulated by in vitro co-culture with OVA and APC, whereas anti-CD3 or PMA-activated $\mathrm{CD}^{+} \mathrm{T}$ cell functions were not inhibited by IL-10 [47]. Taken together, we extrapolated that in the clinical studies, where a reverse relationship between IL-10 and asthmatic responses were 
observed, IL-10's anti-inflammatory effects might be due to its negative regulation on viral-specific effector $\mathrm{CD} 4^{+} \mathrm{T}$ cells $[14,15]$. Plus, RSV-induced Cox-2 gene expression was inhibited by IL-10. Cox-2 is another important mediator involved in RSV-induced inflammation, and Cox-2mediated prostaglandin $\mathrm{E}_{2}\left(\mathrm{PGE}_{2}\right)$ production was reported to repress $\mathrm{RSV}$-induced Th1 response, thereby promoting Th2 responses [48].

In contrast to these anti-inflammatory effects on pathogen-induced inflammation, IL-10 itself might target cell types other than viral-specific effector $\mathrm{T}$ cells. In our study, when $\mathrm{CD}^{+} \mathrm{T}$ cells were depleted by anti-CD4 antibody, IL-10 induced IL-13 up-regulation was not changed. Cell sorting experiments demonstrated that lung CD11b ${ }^{+}$ myeloid cells were able of producing IL-13 by IL-10. Further flow cytometry analysis on the myeloid subsets showed positive intracellular IL-13 staining in CD11 $b^{+}$dendritic cells and NK cells, but not in $\mathrm{CD}_{11} \mathrm{~b}^{+}$macrophages and neutrophils; therefore, the IL-10 OE-induced IL-13producing cell was predicted to be a non-B/non-T (NBNT) cell. In recent years, Th2-cytokine-producing NBNT cells have been reported from several research laboratories $[31,32,49]$, and the phenotypes and functions of these NBNT cells have varied depending on the types of infectious agents and the developmental stages of the NBNT cells. For example, Petersen et al. identified an IL-4- and IL-13-producing Lin $^{-} \mathrm{c}-\mathrm{Kit}^{+} \mathrm{Sca}-1^{+} \mathrm{IL}-17 \mathrm{RB}^{+} \mathrm{CD} 11 \mathrm{~b}^{+} \mathrm{Gr}-1^{\text {mid }}$ T2M (type 2 myeloid cells) that contributes to the cockroach-induced asthmatic exacerbation [49]. Fallon etal. found that during Nippostrongylus brasiliensis infection, IL-25-dependent Th2 cytokine-producing c$\mathrm{kit}^{+} \mathrm{FcER} 1^{-}$NBNT cells played a key role at the initiation of helminth expulsion [31]. Another IL-13-producing myeloid cell is CD1d-dependent NK T cell-activated macrophage which helped to translate $\mathrm{SeV}$ infection into COPD independent of an adaptive immune response [32]. In our study, the IL-10 OE-induced $\mathrm{CD}_{11 \mathrm{~b}}{ }^{+} \mathrm{CD} 11 \mathrm{c}^{+} \mathrm{CD} 49 \mathrm{~b}^{+} \mathrm{F} 4 / 80^{-} \mathrm{Gr}-1^{-}$cell appears to be a different cell type capable of producing robust IL-13 expression in the setting of IL-10 OE.

In our IL-10 OE mouse model, among all the genes that are up-regulated by IL-10, IL-13 and MCP-1 are two most highly induced genes. As IL-13 is a key player in regulating mucus production during allergic airway inflammation [50,51], IL-10 OE alone-induced immunopathological changes in the lung might be due to this highly induced IL-13 production. Furthermore, both IL-10 and IL-13 have been reported to be able to drive MCP-1 expression [52-54]. Besides MCP-1, other chemokines, such as CCL3 and RANTES were also up-regulated. For these chemokines, whether IL-13 plays a direct regulatory role remains to be determined by neutralization studies. Thus, IL-13, in accordance with other chemokines, acts independently of RSV-induced effector $\mathrm{T}$ cells and drives the recruitment of pulmonary leucocytes, which can then lead to the immune pathological changes in the lung. When wild-type mice were infected with RSV, endogenous IL-10 expression showed high expression at day 6 and then decreased by day 8 . This late phase IL-10 gene 'shut down' might have beneficial effects to the host, i.e. preventing a further exacerbation of the immune pathological changes induced by RSV. In our late IL-10 'turn on' model, with the continued presence of IL-10 an additive effect to the RSV-induced immunopathological responses was observed, characterized by exacerbation of airway inflammation and goblet cell hyperplasia. Therefore, investigating the gene regulation of IL-10 during the course of RSV infection appears to be important for understanding this common respiratory disease. It is also possible that the cellular sources of IL-10 change during the course of RSV infection. It is known that IL-10-producing cells include $\mathrm{CD} 4^{+}$and $\mathrm{CD}^{+}$ $\mathrm{T}$ cells, dendritic cells, regulatory $\mathrm{T}$ cells $\left(\mathrm{T}_{\text {reg }}\right)$, monocytes, NK and NK T cells $[12,44,45]$. During both the innate and adaptive immune responses against RSV infection, antigen-specific $\mathrm{CD}^{+}$and $\mathrm{CD}^{+} \mathrm{T}$ cells play critical roles in preventing excess inflammation by producing IL-10 [45]. Clinically, however, it has been reported that monocyte-produced IL-10, especially under dysregulated immune conditions, functions to enhance Th2 responses [12]. Whether our late 'turn on' model explains such clinical observations needs further investigation. With regard to IL-13 production, it is possible that the source of IL-13 varies with the time post-infection. There might also be transitions from the predominance of IL-13-producing anti-viral effector $\mathrm{T}$ cells to the predominance of RSVindependent myeloid cells, which is the target of ongoing studies.

In summary, our study demonstrated a dual role for IL-10 on the immune response to RSV. IL-10 inhibited RSV induced inflammation, but conversely also induced strong Th2-dominant immune responses, possibly via a different mechanism and via a non-CD4 ${ }^{+} \mathrm{T}$ cell subset. Therefore, when two opposite effects were occurring together, as seen in the early IL-10 'turn on' model, the anti-inflammatory effects of IL-10 appear to be masked by the IL-10 'alone' effects. These diverse responses could explain the conflicting reports of IL-10 on the asthmatic phenotype as well as other immune regulations. Although much remains unknown, our study on the dual role of IL-10 provides further mechanistic insight to explain some of the conflicting reports on the role of IL-10 in regulating pathogeninduced inflammation. Multiple factors, such as the timing of IL-10 expression, the concentrations of IL-10 present in the lung, the cellular target of IL-10 induced inflammation and, furthermore, the genetic and epigenetic regulation on IL-10 gene expression after infection need to be considered. Besides, it also suggests that it is critical to determine the appropriate time-frame and cell/molecular targets for considering neutralization of IL-10 in the setting of viralinduced LRTI. 


\section{Acknowledgements}

We thank Dr Keith Bishop at the University of Michigan for providing the anti-CD4 depletion antibodies. We thank Dr J. Erby Wilkinson at the University of Michigan for help with the lung section immunohistology analysis. We also thank Kelli McDonough at the Pediatrics Critical Care Medicine Division for her careful reading and revision on this manuscript. This work was supported by NIH Grants RO1 GM66839-07 to T.P.S. and 5R01AI036302-12 to N.W.L.

\section{Disclosure}

The authors declare that they have no conflicts of interest.

\section{References}

1 Corne JM, Holgate ST. Mechanisms of virus induced exacerbations of asthma. Thorax 1997; 52:380-9.

2 Martinez FD. Definition of pediatric asthma and associated risk factors. Pediatr Pulmonol Suppl 1997; 15:9-12.

3 Schwarze J, Hamelmann E, Bradley KL, Takeda K, Gelfand EW. Respiratory syncytial virus infection results in airway hyperresponsiveness and enhanced airway sensitization to allergen. J Clin Invest 1997; 100:226-33.

4 Teichtahl H, Buckmaster N, Pertnikovs E. The incidence of respiratory tract infection in adults requiring hospitalization for asthma. Chest 1997; 112:591-6.

5 Hogg JC. Childhood viral infection and the pathogenesis of asthma and chronic obstructive lung disease. Am J Respir Crit Care Med 1999; 160:S26-8.

6 Holtzman MJ, Morton JD, Shornick LP et al. Immunity, inflammation, and remodeling in the airway epithelial barrier: epithelial-viral-allergic paradigm. Physiol Rev 2002; 82:19-46.

7 Prince GA, Capiau C, Deschamps M et al. Efficacy and safety studies of a recombinant chimeric respiratory syncytial virus FG glycoprotein vaccine in cotton rats. J Virol 2000; 74:10287-92.

8 Connors M, Giese NA, Kulkarni AB, Firestone CY, Morse HC III, Murphy BR. Enhanced pulmonary histopathology induced by respiratory syncytial virus (RSV) challenge of formalin-inactivated RSV-immunized BALB/c mice is abrogated by depletion of interleukin-4 (IL-4) and IL-10. J Virol 1994; 68:5321-5.

9 Hunter CA, Ellis-Neyes LA, Slifer T et al. IL-10 is required to prevent immune hyperactivity during infection with Trypanosoma cruzi. J Immunol 1997; 158:3311-6.

10 Steidler L, Hans W, Schotte L et al. Treatment of murine colitis by Lactococcus lactis secreting interleukin-10. Science 2000; 289:1352-5.

11 Murai H, Terada A, Mizuno M et al. IL-10 and RANTES are elevated in nasopharyngeal secretions of children with respiratory syncytial virus infection. Allergol Int 2007; 56:157-63.

12 Bont L, Heijnen CJ, Kavelaars A et al. Monocyte IL-10 production during respiratory syncytial virus bronchiolitis is associated with recurrent wheezing in a one-year follow-up study. Am J Respir Crit Care Med 2000; 161:1518-23.

13 Schuurhof A, Janssen R, de Groot $\mathrm{H}$ et al. Local interleukin-10 production during respiratory syncytial virus bronchiolitis is associated with post-bronchiolitis wheeze. Respir Res 2011; 12:121-7.
14 Chung HL, Kim WT, Kim JK et al. Relationship between atopic status and nasal interleukin 10 and 11 levels in infants with respiratory syncytial virus bronchiolitis. Ann Allergy Asthma Immunol 2005; 94:267-72.

15 Takanashi S, Hasegawa Y, Kanehira Y et al. Interleukin-10 level in sputum is reduced in bronchial asthma, COPD and in smokers. Eur Respir J 1999; 14:309-14.

16 Araujo MI, Hoppe B, Medeiros M, Jr et al. Impaired T helper 2 response to aeroallergen in helminth-infected patients with asthma. J Infect Dis 2004; 190:1797-803.

17 Spight D, Zhao B, Haas M, Wert S, Denenberg A, Shanley TP. Immunoregulatory effects of regulated, lung-targeted expression of IL-10 in vivo. Am J Physiol Lung Cell Mol Physiol 2005; 288:L251-65.

18 Tekkanat KK, Maassab HF, Cho DS et al. IL-13-induced airway hyperreactivity during respiratory syncytial virus infection is STAT6 dependent. J Immunol 2001; 166:3542-8.

19 Lindell DM, Lane TE, Lukacs NW. CXCL10/CXCR3-mediated responses promote immunity to respiratory syncytial virus infection by augmenting dendritic cell and $\mathrm{CD} 8(+) \mathrm{T}$ cell efficacy. Eur J Immunol 2008; 38:2168-79.

20 Smit JJ, Lindell DM, Boon L, Kool M, Lambrecht BN, Lukacs NW. The balance between plasmacytoid DC versus conventional DC determines pulmonary immunity to virus infections. PLoS One 2008; 3:e1720

21 Schaller MA, Neupane R, Rudd BD et al. Notch ligand Delta-like 4 regulates disease pathogenesis during respiratory viral infections by modulating Th2 cytokines. J Exp Med 2007; 204:2925-34.

22 Steinhauser ML, Hogaboam CM, Kunkel SL, Lukacs NW, Strieter RM, Standiford TJ. IL-10 is a major mediator of sepsis-induced impairment in lung antibacterial host defense. J Immunol 1999; 162:392-9.

23 Mukherjee S, Lindell DM, Berlin AA et al. IL-17-induced pulmonary pathogenesis during respiratory viral infection and exacerbation of allergic disease. Am J Pathol 2011; 179:248-58.

24 Rudd BD, Smit JJ, Flavell RA et al. Deletion of TLR3 alters the pulmonary immune environment and mucus production during respiratory syncytial virus infection. J Immunol 2006; 176:1937-42.

25 Tekkanat KK, Maassab H, Miller A, Berlin AA, Kunkel SL, Lukacs NW. RANTES (CCL5) production during primary respiratory syncytial virus infection exacerbates airway disease. Eur J Immunol 2002; 32:3276-84.

26 Lukacs NW, Strieter RM, Warmington K, Lincoln P, Chensue SW, Kunkel SL. Differential recruitment of leukocyte populations and alteration of airway hyperreactivity by C-C family chemokines in allergic airway inflammation. J Immunol 1997; 158:4398-404.

27 Schaller MA, Kallal LE, Lukacs NW. A key role for CC chemokine receptor 1 in T-cell-mediated respiratory inflammation. Am J Pathol 2008; 172:386-94.

28 Nakayama T, Yamashita M. Initiation and maintenance of Th2 cell identity. Curr Opin Immunol 2008; 20:265-71.

29 Bishop DK, Chan Wood S, Eichwald EJ, Orosz CG. Immunobiology of allograft rejection in the absence of IFN-gamma: CD8+ effector cells develop independently of CD4+ cells and CD40CD40 ligand interactions. J Immunol 2001; 166:3248-55.

30 Dolgachev V, Petersen BC, Budelsky AL, Berlin AA, Lukacs NW. Pulmonary IL-17E (IL-25) production and IL-17RB+ myeloid cell-derived Th2 cytokine production are dependent upon stem cell factor-induced responses during chronic allergic pulmonary disease. J Immunol 2009; 183:5705-15. 
31 Fallon PG, Ballantyne SJ, Mangan NE et al. Identification of an interleukin (IL)-25-dependent cell population that provides IL-4, IL-5, and IL-13 at the onset of helminth expulsion. J Exp Med 2006; 203:1105-16.

32 Kim EY, Battaile JT, Patel AC et al. Persistent activation of an innate immune response translates respiratory viral infection into chronic lung disease. Nat Med 2008; 14:633-40.

33 Vermaelen K, Pauwels R. Accurate and simple discrimination of mouse pulmonary dendritic cell and macrophage populations by flow cytometry: methodology and new insights. Cytometry A 2004; 61:170-77.

34 Arase H, Saito T, Phillips JH, Lanier LL. Cutting edge: the mouse NK cell-associated antigen recognized by DX 5 monoclonal antibody is CD49b (alpha 2 integrin, very late antigen-2). J Immunol 2001; 167:1141-4.

35 Fleming TJ, Fleming ML, Malek TR. Selective expression of Ly-6G on myeloid lineage cells in mouse bone marrow. RB6-8C5 mAb to granulocyte-differentiation antigen $(\mathrm{Gr}-1)$ detects members of the Ly-6 family. J Immunol 1993; 151:2399-408.

36 Miller AL, Bowlin TL, Lukacs NW. Respiratory syncytial virus-induced chemokine production: linking viral replication to chemokine production in vitro and in vivo. J Infect Dis 2004; 189:1419-30.

37 Foster PS, Hogan SP, Ramsay AJ, Matthaei KI, Young IG. Interleukin 5 deficiency abolishes eosinophilia, airways hyperreactivity, and lung damage in a mouse asthma model. J Exp Med 1996; 183:195-201.

38 Hogan SP, Foster PS. Cellular and molecular mechanisms involved in the regulation of eosinophil trafficking in vivo. Med Res Rev 1996; 16:407-32.

39 John AE, Berlin AA, Lukacs NW. Respiratory syncytial virusinduced CCL5/RANTES contributes to exacerbation of allergic airway inflammation. Eur J Immunol 2003; 33:1677-85.

40 Lukacs NW. Role of chemokines in the pathogenesis of asthma. Nat Rev Immunol 2001; 1:108-16.

41 Haeberle HA, Casola A, Gatalica Z et al. IkappaB kinase is a critical regulator of chemokine expression and lung inflammation in respiratory syncytial virus infection. J Virol 2004; 78:2232-41.

42 Jiang XB, Wang ZD, Zhu Y et al. Inhibition of CD8+ T lymphocytes attenuates respiratory syncytial virus-enhanced allergic inflammation. Respiration 2009; 77:76-84.

43 Smit JJ, Boon L, Lukacs NW. Respiratory virus-induced regulation of asthma-like responses in mice depends upon CD8 T cells and interferon-gamma production. Am J Pathol 2007; 171:1944-51.
44 Lloyd CM, Hawrylowicz CM. Regulatory T cells in asthma. Immunity 2009; 31:438-49.

45 Sun J, Cardani A, Sharma AK et al. Autocrine regulation of pulmonary inflammation by effector T-cell derived IL-10 during infection with respiratory syncytial virus. PLoS Pathog 2011; 7:e1002173.

46 Zuany-Amorim C, Haile S, Leduc D et al. Interleukin-10 inhibits antigen-induced cellular recruitment into the airways of sensitized mice. J Clin Invest 1995; 95:2644-51.

47 Nakagome K, Dohi M, Okunishi K etal. In vivo IL-10 gene delivery suppresses airway eosinophilia and hyperreactivity by down-regulating APC functions and migration without impairing the antigen-specific systemic immune response in a mouse model of allergic airway inflammation. J Immunol 2005; 174:6955-66.

48 Richardson JY, Ottolini MG, Pletneva L et al. Respiratory syncytial virus (RSV) infection induces cyclooxygenase 2: a potential target for RSV therapy. J Immunol 2005; 174:4356-64.

49 Petersen BC, Budelsky AL, Baptist AP, Schaller MA, Lukacs NW. Interleukin-25 induces type 2 cytokine production in a steroidresistant interleukin-17RB+ myeloid population that exacerbates asthmatic pathology. Nat Med 2012; 18:751-8.

50 Lukacs NW, Tekkanat KK, Berlin A et al. Respiratory syncytial virus predisposes mice to augmented allergic airway responses via IL-13-mediated mechanisms. J Immunol 2001; 167:10605.

51 Park JW, Taube C, Yang ES et al. Respiratory syncytial virusinduced airway hyperresponsiveness is independent of IL-13 compared with that induced by allergen. J Allergy Clin Immunol 2003; 112:1078-87.

52 Doucet C, Brouty-Boye D, Pottin-Clemenceau C, Canonica GW, Jasmin C, Azzarone B. Interleukin (IL) 4 and IL-13 act on human lung fibroblasts. Implication in asthma. J Clin Invest 1998; 101:2129-39.

53 Ikeda T, Sato K, Kuwada N et al. Interleukin-10 differently regulates monocyte chemoattractant protein-1 gene expression depending on the environment in a human monoblastic cell line, UG3. J Leukoc Biol 2002; 72:1198-205.

54 Ip WK, Wong CK, Lam CW. Interleukin (IL)-4 and IL-13 up-regulate monocyte chemoattractant protein-1 expression in human bronchial epithelial cells: involvement of p38 mitogenactivated protein kinase, extracellular signal-regulated kinase 1/2 and Janus kinase-2 but not c-Jun NH2-terminal kinase 1/2 signalling pathways. Clin Exp Immunol 2006; 145:162-72. 